\title{
Theoretical and Experimental Study of Diamagnetic and Paramagnetic Products from Thermal and Light-Induced Alkyl Transfer between Zinc or Magnesium Dialkyls and 1,4-Diaza-1,3-butadiene Substrates
}

\author{
Martin Kaupp, ${ }^{\dagger, \ddagger}$ Hermann Stoll, ${ }^{*, \downarrow}$ Heinzwerner Preuss, ${ }^{\ddagger}$ Wolfgang Kaim, ${ }^{*, 8}$ \\ Thomas Stahl, ${ }^{,}$Gerard van Koten, ${ }^{*, \perp}$ Elmo Wissing, ${ }^{\perp}$ Wilberth J. J. Smeets, $\|$ and \\ Anthony L. Spek" \\ Contribution from the Institut für Theoretische Chemie, Universität Stuttgart, \\ Pfaffenwaldring 55, 7000 Stuttgart 80, FRG, Institut für Anorganische Chemie, Universität \\ Stuttgart, Pfaffenwaldring 55, 7000 Stuttgart 80, FRG, Department of Metal Mediated \\ Synthesis, Debye Research Institute, University of Utrecht, Padualaan 8, 3584 CH Utrecht, \\ The Netherlands, and Vakgroep Kristal- en Structuurchemie, University of Utrecht, Padualaan 8 , \\ 3584 CH Utrecht. The Netherlands. Received October 25, 1990
}

\begin{abstract}
Ab}$ initio pseudopotential calculations were used to study species formed in thermal and light-induced alkyl transfer reactions between organometallic compounds $R_{2}^{\prime} M\left(M=Z n, M g ; R^{\prime}=\right.$ alkyl, aryl) and 1,4-diaza-1,3-butadienes $R N=$ $\mathrm{CHCH}=\mathrm{NR}(\mathrm{R}-\mathrm{DAB})$. Geometries of the first isolable intermediates, the chelate complexes $\mathrm{MR}_{2}{ }_{2} \mathrm{R}-\mathrm{DAB}$, have been optimized. The X-ray structure of the crystalline complex $\mathrm{ZnMe}_{2} \cdot t-\mathrm{Bu}-\mathrm{DAB}$ is presented. Its main features are well-reproduced by the calculations on systems with $\mathrm{R}=\mathrm{H}, \mathrm{Me}$. The primary complexes exhibit a destabilized HOMO (antisymmetric M-C $\sigma$-bond combination) and a low-lying LUMO (DAB $\pi^{*}$ orbital). The energy of the HOMO and the intense long-wavelength HOMO-LUMO transition are strongly influenced by the electronegativity of the carbanionic alkyl group and by the electronegativity of the metal. $N, N^{\prime}$-Dimethyl substitution destabilizes the LUMO compared to $\mathrm{R}=\mathrm{H}$. Geometries of the lowest triplet-excited states and the radical anions of the primary chelate complexes can be rationalized in terms of the nodal properties of the frontier orbitals, and indicate $\mathrm{M}-\mathrm{C}$ bond labilization as a prerequisite for alkyl transfer by intramolecular electron transfer in the ground or electronically excited state. In agreement with experiments the $M-C$ bond labilization is generally more pronounced for $\mathrm{M}=\mathrm{Mg}$ than for the $\mathrm{M}=\mathrm{Zn}$ analogues. Calculated vertical and adiabatic electron affinities of the primary complexes are both higher for $\mathrm{M}=\mathrm{Mg}$ than for $\mathrm{M}=\mathrm{Zn}$. Calculations on the synthetically useful $\mathrm{N}$ - and $\mathrm{C}$-alkylated products formed from the primary complexes by the alkyl transfer reaction indicate a rather small energy difference between these two possible collapse products. ESR data of several thermally or photochemically generated paramagnetic products, the anion radicals of the primary chelate complexes and the neutral radicals $\mathrm{MR}^{\prime} \cdot \mathrm{DAB}$, are in agreement with the calculated geometrical and electronic structures. The electronic structures of all organometallic species are studied by means of localized and canonical MOs as well as Mulliken charges and calculated dipole moments. The dependence of reactivity and product selectivity on substituent characteristics $\left(R, R^{\prime}\right)$, solvation, temperature, and excitation wavelength with respect to the LLCT transition is discussed.
\end{abstract}

\section{Introduction}

Organometallic reactions based on single electron transfer (SET) mechanisms have received increasing interest in recent years. ${ }^{1 \mathrm{a}, \mathrm{b}}$ Particularly main group organometallic complexes with unsaturated nitrogen ligands like the $\alpha$-diimines $2,2^{\prime}$-bipyridine and 1,10-phenanthroline often form paramagnetic species. ${ }^{l c, d}$

Van Koten and co-workers ${ }^{2}$ have studied the reactions of dialkylzinc compounds $\mathrm{ZnR}_{2}$ with the aliphatic, mostly $N, N^{\prime}$-ditert-butyl substituted 1,4-diazabutadiene (R-DAB) ligands. The initially formed $N, N^{\prime}$-chelate bonded $1: 1$ adducts (open-chain complexes of the $s$-trans-DAB ligands were not observed) react further under transfer of one alkyl group $R^{\prime}$ from the metal to either an imine carbon or a nitrogen center (cf. Scheme I), depending on the substituents both at the metal and at the chelate ligand and on the reaction conditions. ${ }^{2 f}$ In the series $R^{\prime}=M e$, Et, $i$ - $\mathrm{Pr}, t$ - $\mathrm{Bu}$ (for $\mathrm{R}=t$ - $\mathrm{Bu}$ ) the absorption band causing the intense color of the primary complexes is shifted considerably to longer wavelengths. ${ }^{2 f}$ In the same sequence for $R^{\prime}$ the thermal alkyl transfer reactivity increases significantly with the regioselectivity being shifted from exclusive $\mathrm{N}$-alkylation $\left(\mathrm{R}^{\prime}=\mathrm{Me}, \mathrm{Et}\right)$ to exclusive $C$-alkylation $\left(\mathrm{R}^{\prime}=t-\mathrm{Bu}\right) ; \mathrm{R}^{\prime}=i$ - $\operatorname{Pr}$ leads to $40 \%$ $\mathrm{N}$-alkylation and $60 \% \mathrm{C}$-alkylation. ${ }^{2 f}$ In the same order the amount of radical products formed after complete thermally in-

\footnotetext{
† Present address: Institut für Organische Chemie I, Universităt Erlangen-Nurnberg, Henkestr.42, 8520 Erlangen, F.R.G.

IInstitut for Theoretische Chemie.

Institut für Anorganische Chemie.

- Department of Metal Mediated Synthesis.

"Afdeling Kristal- en Structuurchemie.
}

duced dissociation of an alkyl radical ${ }^{\prime} R^{\prime}$ decreases.

For comparable magnesium analogues no selective transfer reactions have been observed; however, radical products are present in reaction mixtures consisting of, e.g., $2,2^{\prime}$-bipyridine and $\mathbf{R}_{2}^{\prime} \mathbf{M g}^{3}$ Only magnesium diaryls with bulky groups such as mesityl give stable diamagnetic complexes with $2,2^{\prime}$-bipyridine. ${ }^{4}$

Van Koten and co-workers have interpreted their findings with the following general mechanism ${ }^{2 e, f}$ (cf. Scheme I): After initial formation of the tetracoordinated primary complex 3 an intramolecular SET step would lead to a radical pair 4 within the solvent cage for which at least three additional reaction pathways are available. These may lead to two possible internal alkylation "collapse" products 5 and 6 and, through "escape" of an alkyl

(1) (a) Kochi, J. K. Organometallic Mechanisms and Catalysis; Academic Press: New York, 1978. (b) Trogler, W. C., Ed. Organometallic Radical Processes; Elsevier: Amsterdam, 1990. (c) Kaim, W. Acc. Chem. Res. 1985, 18, 160. (d) Kaim, W.; Olbrich-Deussner, B. In ref $1 \mathrm{~b}, \mathrm{p} 173$.

(2) (a) v. Koten, G.; Vrieze, K. Recl. Trav. Chim. Pays-Bas 1981, 100 , 129. (b) v. Koten, G.; Vrieze, K. Adv. Organomet. Chem. 1982, 21, 151. (c) Jastrzebski, J. T. B. H.; Klerks, J. M.; v. Koten, G.; Vrieze, K. J. Organomet. Chem. 1981, 210, C49. (d) Klerks, J. M.; Jastrzebski, J. T. B. H.; v. Koten, G.; Vrieze, K. J. Organomet. Chem. 1982, 224, 107. (e) v. Koten, G.; Jastrzebski, J. T. B. H.; Vrieze, K. J. Organomet. Chem. 1983, 250, 49. (I) v. Koten, G.; In Organometallics in Organic Synthesis; de Mejere, A., tom Dieck, H., Eds.; Springer: New York, 1987. (g) Vrieze, K.; v. Koten, G. In Comprehensive Coordination Chemistry; Wilkinson, G., Ed.; Pergamon Press: New York, 1987; Vol. 2.

(3) (a) Kaim, W. J. Am. Chem. Soc. 1982, 104, 3833. (b) Kaim, W. Chem. Ber. 1981, 114, 3789.

(4) Stahl, T. Diplom Thesis, Institut für Anorganische Chemie, Universitaet Stuttgart 1988. 
Scheme I. Postulated SET Mechanism

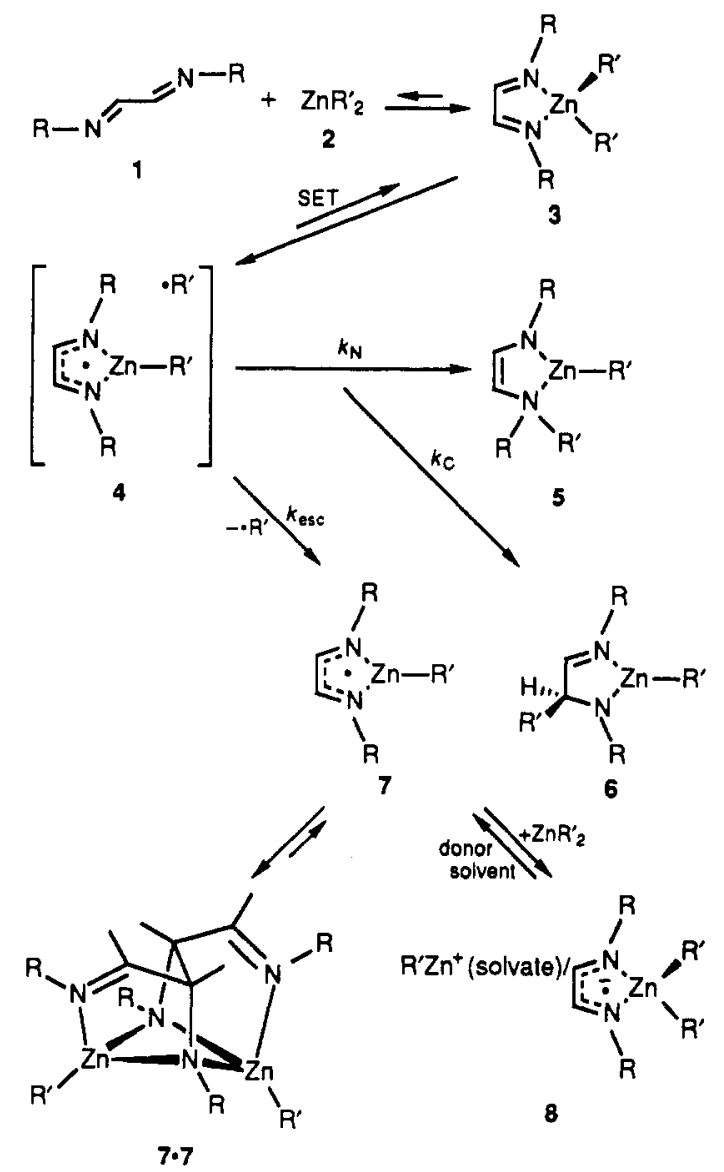

radical, to the formation of the radical 7 which is in equilibrium with its CC-coupled dimer 7.7.2 The neutral radical 7 with coordinatively unsaturated metal may add a carbanion $\left(R^{\prime}\right)^{-}$to form the radical anion 8 of the primary complex $\left(8=3^{\circ-}\right)$.

Recent calculations on the dimethyl compounds 2 and the monomethyl radicals $\mathrm{MMe}^{\circ}(\mathrm{M}=\mathrm{Zn}, \mathrm{Mg})$ demonstrated that 2-valence-electron pseudopotentials for $\mathrm{Zn}$ and $\mathrm{Mg}$ offer a convenient method for $a b$ initio calculations on the medium sized systems of these two elements. ${ }^{5}$ In this paper the ligand 1 , several primary complexes 3 , and some of their radical anions 8 as well as low-lying excited states $3^{*}$ are studied by the pseudopotential method. The solid-state structure for the complex $\mathrm{ZnMe}_{2} \cdot(t-$ Bu-DAB) is presented and compared to the calculations. The radicals 7, which are formed after complete loss of one alkyl radical from the metal in the primary complexes, were also calculated. If a radical pair 4 is indeed present as intermediate in the alkylation reactions, then the properties of the observed radical species are of considerable importance for the rates and the regioselectivity of the reactions. The structures of the alkylation products 5 and 6 were calculated to obtain some guidelines concerning the thermodynamic aspects of these reactions.

One objective of this work lies in the establishment of the electronic structures of the precursor complexes in order to correlate these with spectroscopic properties such as absorption energies or spin distribution in radicals and with reactivity. Particular emphasis is placed on the difference between thermally and photochemically induced reactions, both theoretically and experimentally.

\section{Experimental Section}

All reactions and manipulations were performed in rigorously dried solvents under inert atmosphere. 1,4-Diazabutadiene ligands 1 (R-DAB) and organozinc compounds 2 were prepared according to established procedures. $^{2}$

(5) Kaupp, M.; Stoll, H.; Preuss, H. J. Comp. Chem. 1990, II, 1029.
Table I. Crystal Data and Details of Structure Determination

\begin{tabular}{|c|c|}
\hline & \\
\hline $\begin{array}{l}\text { formula } \\
\text { mol wt } \\
\text { cryst system } \\
\text { space group } \\
a, b, c, \AA \\
\beta, \text { deg } \\
V, \AA^{3} \\
Z \\
D_{\text {calc }}, \mathrm{g} \mathrm{cm}^{-3} \\
F(000) \\
\mu, \mathrm{cm}^{-1} \\
\text { cryst size, mm }\end{array}$ & $\begin{array}{l}\mathrm{C}_{12} \mathrm{H}_{26} \mathrm{~N}_{2} \mathrm{Zn} \\
263.73 \\
\text { monoclinic } \\
P 2_{1} / n(\mathrm{Nr} .14) \\
6.980(1), 20.620(2), 10.854(1) \\
90.97(1) \\
1561.9(3) \\
4 \\
1.121 \\
568 \\
15.9 \\
0.63 \times 0.31 \times 0.17\end{array}$ \\
\hline $\begin{array}{l}\text { temp, } \mathrm{K} \\
\theta_{\min }, \theta_{\max }, \text { deg } \\
\text { radiation } \\
\text { scan type } \\
\Delta \omega, \text { deg } \\
\text { horizontal and vertical aperture, } \\
\text { mm }\end{array}$ & $\begin{array}{l}\text { Collection } \\
294 \\
0.99,25.0 \\
\text { Mo K } \alpha(\mathrm{Zr} \text {-filtered }), 0.71073 \AA \\
\omega / 2 \theta \\
0.50+0.35 \tan \theta \\
3.0,4.0\end{array}$ \\
\hline $\begin{array}{l}\text { dist of cryst to detector, } \mathrm{mm} \\
\text { ref reflcns } \\
\text { data set } \\
\text { total data } \\
\text { total no. of unique data } \\
\text { obsd data }\end{array}$ & $\begin{array}{l}173 \\
2,6,-4 ; 2,-6,-2 \\
h 0: 8 ; k 0: 24 ; l-12: 12 \\
3090 \\
2752 \\
1441[I>2.5 \sigma(I)]\end{array}$ \\
\hline $\begin{array}{l}\text { no. of refined parameters } \\
\text { weighting scheme } \\
\text { final } R, w R, S \\
(\Delta / \sigma)_{\mathrm{av}} \text { in final cycle } \\
\text { min and max resd dens, } \mathrm{e} / \AA^{3}\end{array}$ & $\begin{array}{l}\text { nement } \\
138 \\
w=1.0 / \sigma^{2}(\mathrm{~F}) \\
0.061,0.049,1.51 \\
0.021 \\
-0.38,0.46\end{array}$ \\
\hline
\end{tabular}

(a) $\mathrm{ZnMe}_{2} \cdot(t-\mathrm{Bu}-\mathrm{DAB})$. To a solution of $10 \mathrm{mmol}$ of $t-\mathrm{Bu}-\mathrm{DAB}$ in $20 \mathrm{~mL}$ of diethyl ether was added dropwise 1 equiv of $\mathrm{ZnMe}_{2}$ in hexane ( $\mathrm{M}$ solution). A dark red reaction mixture formed immediately. The solvent was removed in vacuo at ambient temperature and the orange solid product remained. Suitable crystals for $\mathrm{X}$-ray analysis were obtained by crystallization from pentane.

${ }^{1} \mathrm{H}$ NMR in benzene- $d_{6}: \mathrm{Zn}\left(\mathrm{CH}_{3}\right),-0.28(\mathrm{~s}) ; t-\mathrm{Bu}, 1.11(\mathrm{~s})$; imine $\mathrm{H}, 7.32 \mathrm{ppm}(\mathrm{s})$

${ }^{13} \mathrm{C}$ NMR in benzene- $d_{6}: \mathrm{Zn}\left(\mathrm{CH}_{3}\right),-7.4 ; t-\mathrm{Bu}, 29.8,59.7 ;$ imine $\mathrm{C}$, $150.8 \mathrm{ppm}$.

(b) Instrumentation. ${ }^{1} \mathrm{H}$ and ${ }^{13} \mathrm{C}$ NMR spectra were recorded on a Bruker AC-200 spectrometer at $295 \mathrm{~K}$ with chemical shifts relative to $\mathrm{Me}_{4} \mathrm{Si}$ as an external standard. ESR spectra were recorded on a Bruker ESP 300 spectrometer in the $X$ band. Irradiation of samples inside the resonator was performed with a 50-W mercury high-pressure lamp and various cut-off filters (Schott, Mainz, F.R.G.). UV-vis spectra were taken on a Shimadzu UV 160.

(c) Crystallography of $\mathrm{ZnMe}_{2} \cdot(t-\mathrm{Bu}-\mathrm{DAB})$. Structure Determination and Refinement. A red block-shaped crystal was mounted under nitrogen in a Lindemann glass capillary and transferred to an Enraf-Nonius CAD4F diffractometer for data collection. Unit cell parameters were determined from a least-squares treatment of the SET4 setting angles of 25 reflections with $9.0<\vartheta<12.4^{\circ}$. The unit cell parameters were checked for the presence of higher lattice symmetry. ${ }^{6}$ Data were corrected for Lp and for a linear decay (25\%) of the intensity control reflections during the $43 \mathrm{~h}$ of X-ray exposure time but not for absorption. The structure was solved with standard Patterson methods (SHELXS86) and subsequent difference Fourier techniques. Refinement on $F$ was carried out by the full-matrix least-squares method. $\mathrm{H}$ atoms were introduced on calculated positions $(\mathrm{C}-\mathrm{H}=0.98 \mathrm{~A})$ and included in the refinement riding on their carrier atoms. Refinement of all non- $\mathrm{H}$ atoms with anisotropic thermal parameters revealed high thermal motion, in particular for the tert-butyl groups, with corresponding poor geometry. $\mathrm{H}$ atoms were refined with two separated common isotropic thermal parameters $\left(U=0.08\right.$ (2), 0.21 (1) $\AA^{2}$ for $\mathrm{CH}$ and $\mathrm{CH}_{3}$ groups, respectively). Weights were introduced in the final refinement cycles, and convergence was reached at $R=0.061$.

Crystal data and numerical details of the structure determination are given in Table I. Final atomic coordinates and equivalent isotropic

(6) Spek, A. L. J. Appl. Crystallogr. 1988, 21, 578

(7) Sheldrick, G. M. SHELXS86, Program for crystal structure determination. Universitaet of Göttingen, FRG, 1986. 
Table II. Final Coordinates and Equivalent Isotropic Thermal Parameters and Their ESD in Parentheses for $\mathrm{ZnMe}_{2} \cdot(t-\mathrm{Bu}-\mathrm{DAB})$

\begin{tabular}{lrrll}
\hline atom & \multicolumn{1}{c}{$\boldsymbol{x}$} & \multicolumn{1}{c}{$y$} & \multicolumn{1}{c}{$z$} & \multicolumn{1}{c}{$U($ eq) } \\
\hline $\mathrm{Zn}$ & $0.2597(1)$ & $0.09109(5)$ & $0.23095(7)$ & $0.0717(3)$ \\
$\mathrm{N}(1)$ & $0.059(1)$ & $0.0082(3)$ & $0.2536(5)$ & $0.065(3)$ \\
$\mathrm{N}(2)$ & $-0.029(1)$ & $0.1343(3)$ & $0.2177(5)$ & $0.061(3)$ \\
$\mathrm{C}(1)$ & $0.349(1)$ & $0.0816(4)$ & $0.0569(6)$ & $0.097(3)$ \\
$\mathrm{C}(2)$ & $0.373(1)$ & $0.1157(4)$ & $0.3943(6)$ & $0.117(5)$ \\
$\mathrm{C}(3)$ & $0.189(2)$ & $-0.0658(5)$ & $0.400(1)$ & $0.30(1)$ \\
$\mathrm{C}(4)$ & $0.245(2)$ & $-0.0774(5)$ & $0.186(1)$ & $0.40(1)$ \\
$\mathrm{C}(5)$ & $-0.047(2)$ & $-0.1060(5)$ & $0.268(1)$ & $0.224(9)$ \\
$\mathrm{C}(6)$ & $0.120(2)$ & $-0.0588(5)$ & $0.2752(9)$ & $0.090(4)$ \\
$\mathrm{C}(7)$ & $-0.112(1)$ & $0.0242(5)$ & $0.2402(7)$ & $0.070(4)$ \\
$\mathrm{C}(8)$ & $-0.159(1)$ & $0.0930(5)$ & $0.2187(6)$ & $0.074(3)$ \\
$\mathrm{C}(9)$ & $-0.075(1)$ & $0.2041(5)$ & $0.2014(9)$ & $0.085(4)$ \\
$\mathrm{C}(10)$ & $-0.264(2)$ & $0.2158(4)$ & $0.136(1)$ & $0.176(7)$ \\
$\mathrm{C}(11)$ & $0.078(2)$ & $0.2330(4)$ & $0.123(1)$ & $0.168(7)$ \\
$\mathrm{C}(12)$ & $-0.073(2)$ & $0.2337(4)$ & $0.3249(8)$ & $0.185(7)$ \\
\hline
\end{tabular}

${ }^{a} U($ eq $)=1 / 3$ of the trace of the orthogonalized $U$ matrix $\left(\AA^{2}\right)$.

thermal parameters are listed in Table II.

Neutral scattering factors were taken from ref 8 and corrected for anomalous dispersion. ${ }^{9}$ All calculations were performed with SHELX $76^{10}$ and the EUCLID package ${ }^{11}$ (geometrical calculations and illustrations) on a MicroVAX cluster.

\section{Computational Details}

Hartree-Fock calculations have been performed with the semidirect SCF program TURBOMOLE. ${ }^{12}$ MCSCF and CEPA $1^{13}$ calculations were done with the MOLPRO program package ${ }^{13,14}$ SCF calculations on open-shell systems have been performed within the RHF scheme unless stated otherwise. The space-filling tert-butyl groups on the imine nitrogens, which are present in most experimental examples, have been replaced by hydrogen atoms in the calculations. In some calculations methyl groups have been used to study the electronic influence of $N$-alkyl substitution.

A comparison of several pseudopotentials and valence basis sets as well as correlation effects for organozinc and organomagnesium compounds has been published elsewhere. ${ }^{5}$ SCF calculations with 2-valence-electron pseudopotentials and $[4 s 2 p] /(3 s 2 p)$ valence basis sets on the metals and He-core pseudopotentials with $[4 \mathrm{~s} 4 \mathrm{p}] /(2 \mathrm{~s} 2 \mathrm{p})$ basis sets on the first-row elements and a $[4 s] /(2 s)$ basis set on hydrogen ${ }^{15}$ have been found to yield satisfactory geometries as well as other properties. ${ }^{5}$ Calculations on the model complex $\mathrm{ZnH}_{2}$. DAB (see Table III) also show the $\mathrm{Zn}$-DAB-ring geometries with this combination to be in good agreement with calcula. tions including added polarization functions on the first-row atoms and on hydrogen ${ }^{15}$ and even with calculations using a Ne-core pseudopotential16 $^{16}$ and an extended basis set ${ }^{16}$ on zinc and the [9s5pld] /(3s2pld) all-electron basis set of Dunning and Hay ${ }^{15}$ on carbon and nitrogen. Therefore this valence-only description with $\mathrm{TZ}+2 \mathrm{P}$ quality for the metal and $\mathrm{DZ}$ quality for the other atoms has been employed for all geometry optimizations as well as for all population analyses and dipole moment and orbital energy calculations.

As Table IV shows for the calculation of electron affinities and energies for transitions from the ground state to the lowest excited triplet state $\left(S_{0} \rightarrow T_{1}\right)$, polarization functions on the first-row atoms and hydrogen give a better relative description of the closed-shell ground state whereas diffuse functions on the atoms bound directly to the metal (an sp set for the first-row atoms ${ }^{17}$ and an $s$ function with $\alpha=0.028$ on

(8) Cromer, D. T.; Mann, J. B. Acta Crystallogr. 1968, A24, 321.

(9) Cromer, D. T.; Liberman, D. J. Chem. Phys. 1970, 53, 1891.

(10) Sheldrick, G. M. SHELX76, Crystal structure analysis package. University of Cambridge, England, 1976.

(11) Spek, A. L. The EUCLID Package. In Computational Crystallography; Sayre, D., Ed.; Clarendon Press: Oxford, 1982; p 528.

(12) Häser, M.: Ahlrichs, R. J. Comp. Chem. 1988, 10, 104

(13) (a) Meyer, W. J. Chem. Phys. 1973, 58, 1017. (b) Meyer, W. J. Chem. Phys. 1976, 64, 2901.

(14) Werner, H. J., University of Bielefeld; Meyer, W., University of Kaiserslautern; Program MOLPRo, 1987 (see e.g. ref 18).

(15) Dunning, T. H.; Hay, P. J. In Methods of Electronic Structure Theory Schaefer, H. F., III, Ed.; Plenum Press: New York, 1977; Vol. 3, p I.

(16) Dolg, M.; Wedig, U.; Stoll, H.; Preuss, H. J. Chem. Phys. 1987, 86, 866.

(17) Spitznagel, G. W.; Clark, T.; Chandrasekhar, J.; Schleyer, P. v. R. J. Comp. Chem. 1982, 3, 363.

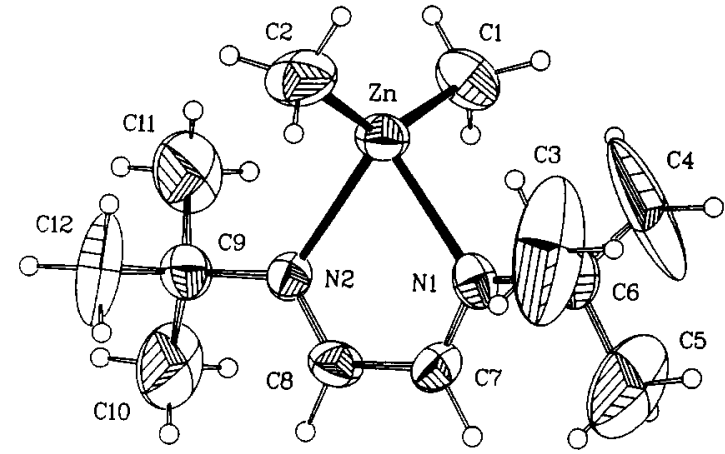

Figure 1. Thermal motion ellipsoid plot (30\% probability level) for $\mathrm{ZnMe}_{2} \cdot(t-\mathrm{Bu}-\mathrm{DAB})$ with adopted atom labeling. Note that for comparison with computational results a different numbering is employed (see Table VI)

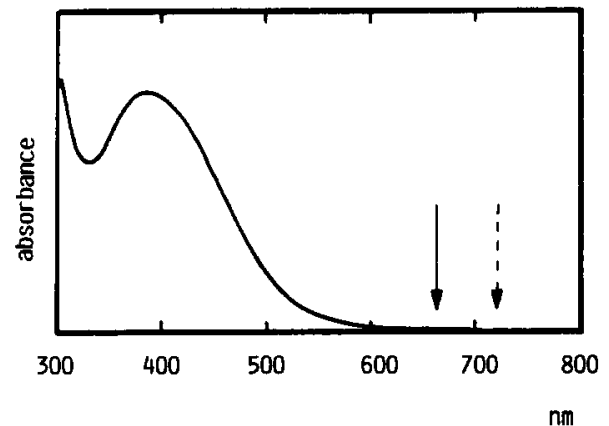

Figure 2. UV-vis absorption spectrum of $\mathrm{ZnMe}_{2} \cdot(t-\mathrm{Bu}-\mathrm{DAB})$ in benzene. Arrows indicate the cut-off filters used in radical generation experiments (see text).

hydrogen) and valence correlation (calculated by the CEPAl method ${ }^{13}$ ) favor the open-shell systems. These counteracting effects cause results with the DZ basis set augmented by a diffuse set ("v.0.+") to be in relatively good agreement with the CEPAl calculations employing a basis set including polarization and diffuse functions ("v.o.p.+" /CEPA1). For the considerably larger systems to be studied in this work, therefore this combination "v.o.t" has been employed to calculate transition energies and electron affinities at the SCF level.

For transitions to the lowest excited singlet state $\left(\mathrm{S}_{0} \rightarrow \mathrm{S}_{1}\right), \triangle \mathrm{MCSCF}$ calculations, with the active space composed of the two orbitals participating in the transition, had to be performed. To avoid root flipping, ${ }^{18}$ the MO coefficients have been optimized for the average of the first two $\mathrm{CI}$ eigenvalues. The "v.o.t" basis set combination was employed here too.

The center of gravity was chosen as the gauge for the dipole moment vector in anionic species.

Geometry optimizations for primary complexes with $R^{\prime}=H, M e, C F_{3}$ have been restricted to $C_{2,}$ symmetry while calculations with $\mathrm{R}^{\prime}=\mathrm{Et}$, $i$-Pr were done with $C_{2}$ symmetry. For the optimization of the $\mathrm{T}_{1}$ state of $\mathrm{ZnMe}_{2} \cdot \mathrm{DAB}$ symmetry restrictions were completely released but no significant deviation from $C_{2,}$ symmetry was observed. The radicals MMe.DAB have been optimized within $C_{s}$ symmetry while for the alkylation products no symmetry could be employed (for these species the $S$ configuration at the asymmetric centers was chosen).

\section{Spectroscopic Results}

(a) The Structure of $\mathrm{ZnMe}_{2} \cdot(t-\mathrm{Bu}-\mathrm{DAB})$ in the Solid State. Figure 1 shows the pseudotetrahedral coordination around zinc with an angle $\mathrm{C}_{1} \mathrm{ZnC}_{2}$ of $137.3^{\circ}$ and an $\mathrm{N}_{1} \mathrm{ZnN}$ bite angle of $75.0^{\circ}$ (cf. Table VI) for the solid-state structure of the 1:1 complex $\mathrm{ZnMe}_{2} \cdot(t-\mathrm{Bu}-\mathrm{DAB})$. The observed structural features are discussed in detail in section V.a, together with the computational results for the primary complexes. Complete geometrical parameters are available as supplementary material.

(b) Electronic Absorption Spectra. Several 1:1 coordination complexes 3 were prepared in hydrocarbon or ether solvents (Scheme I). All complexes studied are colored with widely varying

(18) Werner, H. J. Adv. Chem. Phys. 1987, 69, 1 
Table III. Geometry Parameters of $\mathrm{ZnH}_{2} \cdot \mathrm{DAB}$ with Different Basis Sets

\begin{tabular}{|c|c|c|c|c|c|c|c|}
\hline distances, pm & ext. ${ }^{a}$ & v.o.p. ${ }^{6}$ & v.o. ${ }^{c}$ & angles, deg & ext. ${ }^{a}$ & v.o.p. ${ }^{b}$ & v.0. \\
\hline $\begin{array}{l}\mathrm{Zn}-\mathrm{H}_{1} \\
\mathrm{Zn}-\mathrm{N}_{1} \\
\mathrm{~N}_{1}-\mathrm{C}_{1} \\
\mathrm{C}_{1}-\mathrm{C}_{2} \\
\mathrm{~N}_{1}-\mathrm{H}_{3} \\
\mathrm{C}_{1}-\mathrm{H}_{3}\end{array}$ & $\begin{array}{l}161 \\
228 \\
124 \\
151 \\
100 \\
108\end{array}$ & $\begin{array}{l}162 \\
227 \\
125 \\
150 \\
100 \\
108\end{array}$ & $\begin{array}{l}161 \\
226 \\
125 \\
149 \\
101 \\
108\end{array}$ & $\begin{array}{l}\mathrm{H}_{1}-\mathrm{Zn}-\mathrm{H}_{2} \\
\mathrm{~N}_{1}-\mathrm{Zn}-\mathrm{N}_{2} \\
\mathrm{Zn}_{\mathrm{n}}-\mathrm{N}_{1}-\mathrm{C}_{1} \\
\mathrm{~N}_{1}-\mathrm{C}_{1}-\mathrm{C}_{2} \\
\mathrm{~N}_{1}-\mathrm{Zn}-\mathrm{H}_{1} \\
\mathrm{H}_{3}-\mathrm{N}_{1}-\mathrm{Zn} \\
\mathrm{H}_{5}-\mathrm{C}_{1}-\mathrm{C}_{2}\end{array}$ & $\begin{array}{r}146 \\
72 \\
116 \\
118 \\
104 \\
125 \\
119 \\
\end{array}$ & $\begin{array}{r}146 \\
71 \\
118 \\
117 \\
104 \\
125 \\
119 \\
\end{array}$ & $\begin{array}{r}145 \\
72 \\
116 \\
118 \\
104 \\
125 \\
120 \\
\end{array}$ \\
\hline
\end{tabular}

${ }^{a}$ Extended calculations with $\mathrm{Ne}$ core for $\mathrm{Zn}$ and all-electron basis sets for all other atoms. ${ }^{b}$ Valence-only calculations, including polarization functions on first-row atoms and $\mathrm{H}$. ${ }^{c}$ Valence-only calculations with $\mathrm{DZ}$ quality on first-row atoms and $\mathrm{H}$.

Table IV. Electron Affinities and $S_{0} \rightarrow T_{1}$ Transition Energies of $\mathrm{ZnH}_{2} \cdot \mathrm{DAB}$ with Different Methods<smiles>[H][Z]1=C(C)N(C)N[Y]1([H])[H]</smiles>

\begin{tabular}{|c|c|c|}
\hline & $\mathrm{EA}, \mathrm{eV}$ & $\Delta E\left(\mathrm{~S}_{0} \rightarrow \mathrm{T}_{1}\right), \mathrm{eV}$ \\
\hline ext. ${ }^{a}$ & -0.3057 & 3.9372 \\
\hline v.0.p..$^{b}$ & -0.4495 & 4.0047 \\
\hline v. $0 .^{c}$ & -0.1332 & 3.5533 \\
\hline v.o.p. $+^{b, d}$ & -0.1544 & 3.8602 \\
\hline v.o.t $+^{c, d}$ & 0.0231 & 3.5196 \\
\hline v.o.p. ${ }^{b} /$ CEPA 1 & -0.1553 & 3.6431 \\
\hline v.o.p. $+b, d / C E P A 1$ & 0.2556 & 3.4085 \\
\hline
\end{tabular}

${ }^{a}$ Extended calculations with $\mathrm{Ne}$ core for $\mathrm{Zn}$ and all-electron basis sets for all other atoms. ${ }^{b}$ Valence-only calculations, including polarization functions on first-row atoms and $\mathrm{H}$. ${ }^{c}$ Valence-only calculations with $\mathrm{DZ}$ quality on first-row atoms and $\mathrm{H}$. ${ }^{d}$ Diffuse functions on $\mathrm{N}$, $\mathrm{H}_{1}$, and $\mathrm{H}_{2}$ added.

absorption maxima; ${ }^{2 f}$ a typical absorption spectrum is shown in Figure 2. Two measurements of extinction coefficients of the thermally more stable systems with $R^{\prime}=$ Me gave values in the order of $10^{3} \mathrm{M}^{-1} \mathrm{~cm}^{-1}$.

(c) Radical Generation and ESR Spectra Analysis. While some systems 1 and 2 yielded ESR-detectable radicals or radical ions simply on mixing at $300 \mathrm{~K}$, other complexes 3 had to be irradiated with a mercury lamp to produce paramagnetic species. Cut-off filters were used to study the wavelength dependence of the radical formation in one instance ( $\mathrm{ZnMe}_{2} \cdot(t-\mathrm{Bu}-\mathrm{DAB})$ in hydrocarbons); a $715-\mathrm{nm}$ filter effectively prevented radical formation whereas a $665-\mathrm{nm}$ filter still allowed radical production (Figure 2 ). The $\mathrm{ZnEt}_{2^{*}}(t-\mathrm{Bu}-\mathrm{DAB})$ system was studied in diethyl ether at $190 \mathrm{~K}$ to preclude thermal electron transfer; a wavelength dependence was noted with regard to the amount of radical produced within a certain time (Table V). Figure 3 clearly illustrates that different paramagnetic species were formed from that same system, depending on thermal or photochemical electron transfer. The role of the solvent was addressed by experiments as shown in Figure 4. Figure 5 demonstrates the effect of different kinds of steric bulk in the substituents at zinc.

Although the ${ }^{1} \mathrm{H}$ and ${ }^{14} \mathrm{~N}$ ESR hyperfine structures could be readily interpreted without the help of computer simulation, the coupling from low-abundant isotopes ${ }^{13} \mathrm{C}(1.1 \%, I=1 / 2)$ and ${ }^{67} \mathrm{Zn}$ (4.12\% natural abundance, $l=5 / 2$ ) was confirmed with spectra synthesis (Figure $4 b, c$ ). One ${ }^{67} \mathrm{Zn}$ nucleus in the radical gives rise to six satellite lines around the main feature, each of which corresponds to $4.12 \% / 6=0.69 \%$ of relative intensity. The most intense ${ }^{13} \mathrm{C}$ satellite signals arise from a hyperfine interaction with the six equivalent methyl groups in the $t-\mathrm{Bu}-\mathrm{DAB}$ anion radical, the probability for a molecule having one such ${ }^{13} \mathrm{C}$ nucleus at such a position is $6 \times 0.011 \times(1-0.011)^{5}=0.0624$. Because of the doublet splitting $(I=1 / 2)$, one such satellite has a relative probability of $3.12 \%$. The magnitudes of the detected ${ }^{13} \mathrm{C}$ isotope splittings are similar to the values observed by Clopath and von Zelewsky ${ }^{19}$ for $\mathrm{Zn}(\mathrm{Hal}) \cdot(t-\mathrm{Bu}-\mathrm{DAB})$ radicals, who interpreted
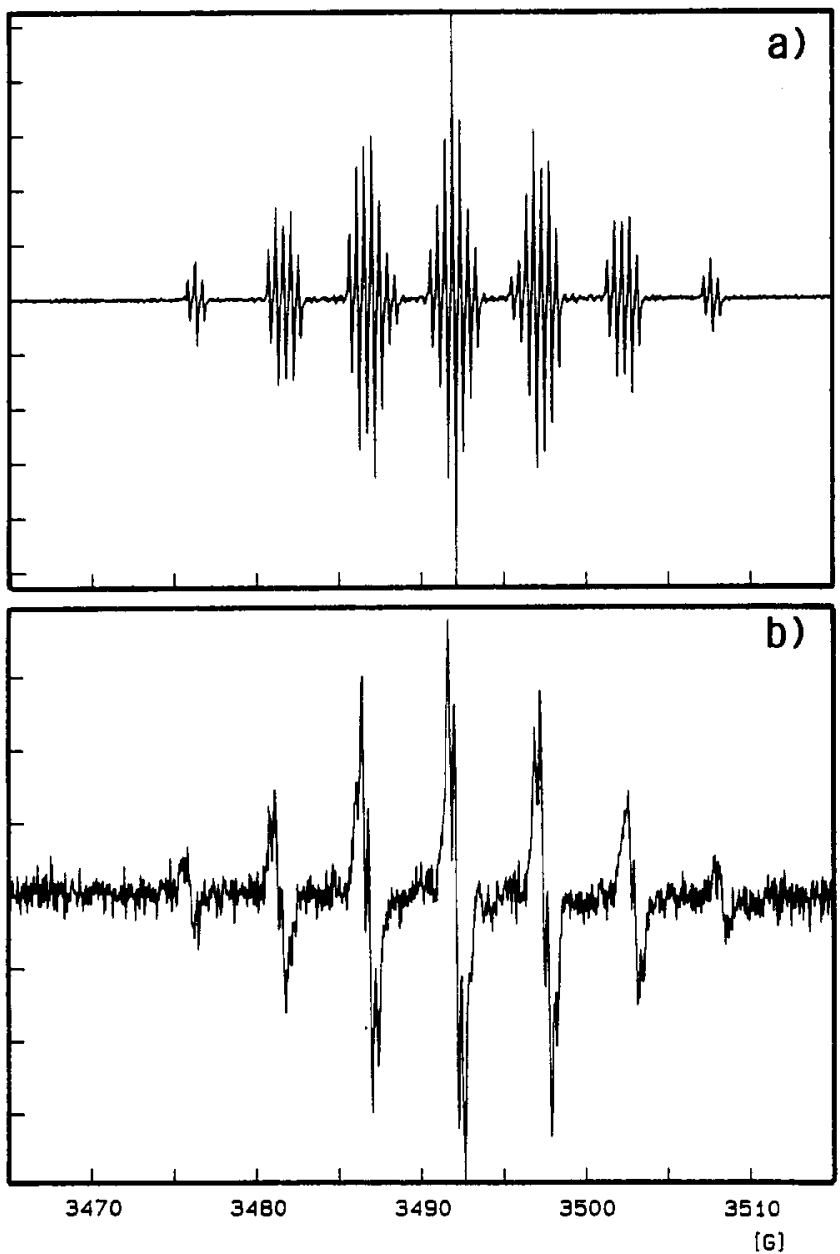

Figure 3. ESR spectra of radical complexes produced in diethyl ether solution from $\mathrm{ZnEt}_{2^{\circ}}(t-\mathrm{Bu}-\mathrm{DAB})$ : (a) thermally at $300 \mathrm{~K}$, (b) photolytically (wavelength $<515 \mathrm{~nm}$ ) at $190 \mathrm{~K}$.

them as overlapping signals from diimine and quaternary tert-butyl carbon centers. The ${ }^{67} \mathrm{Zn}$ splittings were found to be much larger for the halide and pseudohalide complexes $\left(>0.4 \mathrm{mT}^{19}\right)$ than for the organometallics described here. Coupling of the imine carbon atoms should be rather small; assuming McConnell-derived ${ }^{20}$ "experimental" spin populations of $\varphi_{\mathrm{CH}}=0.2$ for these carbon centers and of $\varphi_{\mathrm{N}}=0.3$ for the imine nitrogen atoms the application of a Karplus-Fraenkel equation, ${ }^{20} a_{\mathrm{CH}}=(3.56 \mathrm{mT}) \varphi_{\mathrm{CH}}$ $-(1.39 \mathrm{mT})\left(\varphi_{\mathrm{CH}}+\varphi_{\mathrm{N}}\right)$, leads to a number of only $0.017 \mathrm{mT}$.

The rather simple hyperfine pattern and the relatively large ESR coupling constants of the $t$-Bu-DAB anion radical system permit a straightforward distinction between two different kinds of radical complexes formed as stable escape products in the SET reaction. Radical type $A$ (see Table $V$ ) shows relatively large differences between ${ }^{14} \mathrm{~N}(1,4)$ and ${ }^{1} \mathrm{H}(2,3)$ splittings of the 1,4 . diazabutadiene ligand; however, there is some small additional

(19) Clopath, P.; von Zelewsky, A. Helv. Chim. Acta 1972, 55, 52.

(20) Gerson, F. High Resolution E.S.R. Spectroscopy; Wiley: London, 
Table V. ESR Characteristics of Radical Products from Thermal and Light-Induced Electron Transfer

\begin{tabular}{|c|c|c|c|c|c|c|c|c|}
\hline \multirow{2}{*}{$\begin{array}{c}\text { metal } \\
\text { fragment }\end{array}$} & \multirow[b]{2}{*}{ ligand } & \multirow[b]{2}{*}{ solvent } & \multirow[b]{2}{*}{ radical generation ${ }^{a}$} & \multirow[b]{2}{*}{$\lambda_{\max }$ p.c. ${ }^{b}$} & \multicolumn{3}{|c|}{ ESR coupling constants ${ }^{c}$} & \multirow{2}{*}{$\begin{array}{l}\text { type of } \\
\text { radicald }^{d}\end{array}$} \\
\hline & & & & & $a\left({ }^{14} \mathrm{~N}\right)$ & $a\left({ }^{1} \mathrm{H}\right)$ & $a(\mathrm{x})$ & \\
\hline $\begin{array}{l}\mathrm{ZnMe}_{2} \\
\mathrm{ZnMe}_{2} \\
\mathrm{ZnMe}_{2} \\
\mathrm{ZnMe}_{2}\end{array}$ & $\begin{array}{l}t-\mathrm{BuDAB} \\
t-\mathrm{BuDAB} \\
t-\mathrm{BuDAB} \\
t-\mathrm{BuDAB}\end{array}$ & $\begin{array}{l}\text { hexane } \\
\text { benzene } \\
\text { benzene } \\
\text { THF }\end{array}$ & $\begin{array}{l}h v:>550 \mathrm{~nm} \\
h v:>665 \mathrm{~nm} \\
h v:>715 \mathrm{~nm} \\
\Delta: 300 \mathrm{~K}\end{array}$ & $\begin{array}{l}388 \\
388 \\
388 \\
381(\text { \& } 1200)\end{array}$ & $\begin{array}{l}0.485 \\
0.485 \\
0.552\end{array}$ & $\begin{array}{l}0.585 \\
0.585 \\
\quad \text { no esr sig } \\
0.552\end{array}$ & $\begin{array}{l}0.050\left(\mathrm{ZnCH}_{3}\right) \\
0.050\left(\mathrm{ZnCH}_{3}\right) \\
\mathrm{al} \\
0.298\left(6 \times \times^{13} \mathrm{C}\right) \\
0.179\left(1 \times{ }^{67} \mathrm{Zn}\right)\end{array}$ & $\begin{array}{l}\text { A } \\
\text { A } \\
/ \\
\text { B }\end{array}$ \\
\hline $\begin{array}{l}\mathrm{ZnMe}_{2} \\
\mathrm{ZnMe}_{2} \\
\mathrm{ZnEt}_{2} \\
\mathrm{ZnEt}_{2} \\
\mathrm{ZnEt}_{2} \\
\mathrm{Zn}-i-\mathrm{Pr}_{2}\end{array}$ & $\begin{array}{l}t \text {-AmylDAB } \\
o-\text { XylMDAB } \\
t \text {-BuDAB } \\
t \text {-BuDAB } \\
t \text {-BuDAB } \\
t-\text { BuDAB }\end{array}$ & $\begin{array}{l}\mathrm{THF} \\
\mathrm{THF} \\
\mathrm{Et}_{2} \mathrm{O} \\
\mathrm{Et}_{2} \mathrm{O} \\
\mathrm{Et}_{2} \mathrm{O} \\
\mathrm{Et}_{2} \mathrm{O}\end{array}$ & $\begin{array}{l}\Delta: 300 \mathrm{~K} \\
h v:>320 \mathrm{~nm} \\
\Delta: 300 \mathrm{~K} \\
h \nu:>515 \mathrm{~nm}(190 \mathrm{~K}) \\
h v:>550 \mathrm{~nm}(190 \mathrm{~K}) \\
\Delta: 300 \mathrm{~K}\end{array}$ & $\begin{array}{l}400(\mathrm{sh}) \\
340\end{array}$ & $\begin{array}{l}0.552 \\
0.466 \\
0.491 \\
0.528 \\
0.528^{8} \\
0.490\end{array}$ & $\begin{array}{l}0.552 \\
0.672\left(\mathrm{CH}_{3}\right) \\
0.585 \\
0.560 \\
0.560^{8} \\
0.585\end{array}$ & $\begin{array}{l}\text { HFS } f \\
0.043\left(\mathrm{ZnCH}_{2}\right) \\
\\
0.026\left(\mathrm{ZnCH}^{13}\right) \\
0.29\left(6 \times \times^{13} \mathrm{C}\right) \\
0.18\left(1 \times{ }^{67} \mathrm{Zn}\right)\end{array}$ & $\begin{array}{l}\text { B } \\
\text { B } \\
\text { A } \\
\text { B } \\
\mathbf{B}^{*} \\
\text { A }\end{array}$ \\
\hline $\begin{array}{l}\mathrm{Zn}-i-\mathrm{Pr}_{2} \\
\mathrm{Zn}-t-\mathrm{Bu}_{2} \\
\mathrm{Zn}-t-\mathrm{Bu}_{2} \\
\mathrm{Zn}(0-\mathrm{Xyl})_{2} \\
\mathrm{ZnPh} 2\end{array}$ & $\begin{array}{l}t \text {-BuDAB } \\
t \text {-BuDAB } \\
t \text {-BuDAB } \\
t \text {-BuDAB } \\
t \text {-BuDAB }\end{array}$ & $\begin{array}{l}\mathrm{Et}_{2} \mathrm{O} \\
\mathrm{Et}_{2} \mathrm{O} \\
\mathrm{Et}_{2} \mathrm{O} \\
\mathrm{Et}_{2} \mathrm{O} \\
\mathrm{THF}\end{array}$ & $\begin{array}{l}\Delta: 300 \mathrm{~K} \text { after } 24 \mathrm{~h} \\
\Delta: 300 \mathrm{~K} \\
\Delta: 300 \mathrm{~K} \text { after } 24 \mathrm{~h} \\
h \nu:>435 \mathrm{~nm} \\
h \nu:>475 \mathrm{~nm}\end{array}$ & $\begin{array}{l}370 \\
367(\epsilon 600)\end{array}$ & $\begin{array}{l}f \\
0.508^{h} \\
0.557 \\
0.470 \\
0.553\end{array}$ & $\begin{array}{l}f \\
0.578^{h} \\
0.557 \\
0.596 \\
0.553\end{array}$ & $\begin{array}{l}0.287\left(6 x^{13} \mathrm{C}\right) \\
0.14\left(1 \times^{67} \mathrm{Zn}\right)\end{array}$ & $\begin{array}{l}\text { B } \\
\text { A } \\
\text { B } \\
\text { A } \\
\text { B }\end{array}$ \\
\hline
\end{tabular}

${ }^{a}$ Photolysis $(h \nu)$ with a mercury lamp and cutoff filters. ${ }^{b}$ Absorption maximum $\lambda_{\max }$ for precursor complex (nm), extinction coefficients $\epsilon\left(\mathrm{M}^{-1}\right.$ $\left.\mathrm{cm}^{-1}\right){ }^{c} \operatorname{In~} \mathrm{mT}(1 \mathrm{mT}=10 \mathrm{G})$. ${ }^{d} \mathrm{~A}$, neutral radicals 7; B, anion radicals 8. 'The 1,4-di-o-xylyl-2,3-dimethyl-1,4-diazabutadiene ligand was employed. ${ }^{f}$ Additional hyperfine structure not analyzed. 8 Formed in low concentration. ${ }^{h}$ Measured at $200 \mathrm{~K}$.

coupling from $\alpha$-protons of one metal-bonded alkyl group (see Figures $3 a, 4 a$, and $5 a, c)$. Radicals of type B (see Table V) do not exhibit such metal-alkyl coupling; they also show larger ${ }^{14} \mathrm{~N}$ splitting which often coincides with the olefin proton coupling (see Figures $3 b, 4 b$, and $5 b, d)$.

We identify radicals $A$ with the neutral systems $\left(\mathrm{ZnR}^{\prime}\right)^{+} \cdot(\mathrm{R}-$ DAB) ${ }^{\circ-}$ (7) (cf. Scheme I). The paramagnetic species $B$ are interpreted as anion radicals $\left(\mathrm{ZnR}_{2}^{\prime}\right) \cdot(\mathrm{R}-\mathrm{DAB})^{\cdot-}(\mathbf{8})$ which may be formed in a secondary, solvent-affected equilibrium reaction with one more organometallic species $\mathrm{ZnR}_{2}^{\prime}$. As countercation we assume strongly solvated species $\mathrm{ZnR}^{\prime+}$; radicals $\mathrm{B}$ are particularly easily formed in cation complexing THF (Figure $4 \mathrm{~b}$ ). The $\mathrm{ZnMe}$ fragment, e.g., yields radicals 7 from irradiation $(<665$ $\mathrm{nm}$ ) or thermal methods in hydrocarbons and ether whereas species 8 was produced in THF. Isopropyl- and tert-butylzinc containing neutral radicals, 7 , were formed thermally $(300 \mathrm{~K})$ in diethyl ether just as the methyl and ethyl analogues; the tert-butyl system showed a slow conversion to the radical anion 8 (Figure 5a,b).

The possible formation of anion radicals of the starting materials, of neutral radical complexes or even of cation radical complexes formed from an anion radical ligand and two $\left(\mathrm{MR}^{\prime}\right)^{+}$ cations has been discussed before. ${ }^{1 \mathrm{c}}$ It was not always possible to distinguish unambiguously between these possibilities even after employing double or triple resonance techniques. ${ }^{21}$ Such an ambivalence, $\mathbf{7} \leftrightarrow \mathbf{8}$, has been observed earlier for $R^{\prime}=$ halides (type 7 species) and $\mathrm{R}^{\prime}=$ pseudohalides (type 8 species). ${ }^{19}$

The ESR parameters are compatible with the assignment given above. The $\alpha$ proton splitting for radical type 7 is caused by hyperconjugation between $\sigma(\mathrm{C}-\mathrm{H})$ bonds of the zinc-alkyl substituent and $\pi^{*}(t-\mathrm{Bu}-\mathrm{DAB})$ in the calculated trigonal planar arrangement at zinc (cf. Table XII); such an interaction is not possible for anion radical 8 with approximately tetrahedrally coordinated zinc.

The ratio for this $\alpha$ proton coupling between isopropyl and ethyl groups on one side and methyl on the other side is relatively large. The $R$ values as defined by McKinney and Geske (eq $1^{22 a}$ ) are 0.86 for the ethyl and 0.52 for the isopropyl system, signifying less restricted rotation of these substituents than in corresponding hydrocarbon radical ions. ${ }^{20}$ The simple reason for such rather

(21) Kaim, W.; Lubitz, W. Angew. Chem. 1983, 95, 915; Angew. Chem. Int. Ed. Engl. 1983, 22, 892; Angew. Chem. Suppl. 1983, 1209.

(22) (a) McKinney, T. M.; Geske, D. H. J. Am. Chem. Soc. 1967, 89 2806. (b) Bock, H.; Kaim, W. Acc. Chem. Res. 1982, 15, 9. free rotation is the much longer and more ionic bond in $\mathrm{Zn}-\mathrm{C}$ (alkyl) versus $\mathrm{C}-\mathrm{C}$ (alkyl) systems.

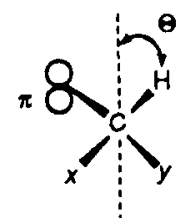

$$
\begin{gathered}
R=\frac{a_{\mathrm{H}}(\mathrm{CHXY})}{a_{\mathrm{H}}\left(\mathrm{CH}_{3}\right)}=\frac{\left\langle\cos ^{2} \theta\right\rangle}{0.5} \\
R=1, \text { free rotation }
\end{gathered}
$$

$$
\begin{gathered}
R=0.5, \text { frozen conformation }\left(\mathrm{CH}_{2} \mathrm{X}\right) \\
R=0, \text { frozen conformation }\left(\mathrm{CHX}_{2}\right)
\end{gathered}
$$

$\theta$ is the dihedral angle between the $\pi$ axis and the $\mathrm{Zn}-\mathrm{C}-\mathrm{H}$ plane. The different ${ }^{14} \mathrm{~N}$ splitting for the two radical types is confirmed by the results of our pseudopotential calculations (see below).

\section{Computational Results}

(a) Primary Complexes with $R^{\prime}=H, M e, E t, i-\operatorname{Pr}(R=H)$. The most important internal coordinates of the main skeleton of all optimized primary complexes of some compounds $\mathbf{M R}_{2}^{\prime}$ and of the free DAB-ligand are shown in Table VI. Geometrical parameters from the X-ray structure of $\mathrm{ZnMe}_{2} \cdot(t-\mathrm{Bu}-\mathrm{DAB})$ are included for a comparison with the calculated geometries of $\mathrm{ZnMe}_{2} \cdot \mathrm{DAB}$ and $\mathrm{ZnMe} \cdot(\mathrm{Me}-\mathrm{DAB})$.

Obviously the calculated $\mathrm{ZnN}$ distance is significantly longer than the experimental value. This is due to the very flat potential curve for the dative $\mathrm{MN}$ bond, ${ }^{23}$ leading to large changes in distance for rather small energy differences. Such differences may be caused by the neglect of valence-shell contracting core-valence correlation for $\mathrm{Zn}, 5$ by differences between gas-phase and solidstate structures (for $\mathrm{Zn}\left\{\left(\mathrm{CH}_{2}\right)_{3} \mathrm{NMe}_{2}\right\}_{2}$ the $\mathrm{ZnN}$ distance in the gas phase has been found to be $8-9 \mathrm{pm}$ larger than that in the solid state ${ }^{23}$ ), and by the "substitution" of tert-butyl groups on nitrogen by hydrogen atoms. The other parameters indicate excellent agreement between theory and experiment.

A comparison of the calculated data for $\mathrm{R}^{\prime}=\mathrm{Me}, \mathrm{Et}, i-\mathrm{Pr}$ and $\mathbf{M}=\mathrm{Zn}$ shows only very slight differences. The same holds true for $\mathrm{M}=\mathrm{Mg}$. $\mathrm{R}^{\prime}=\mathrm{H}$ leads to significant changes in the envi-

(23) (a) Dekker, J.; Boersma, J.; Fenholt, L.; Haaland, A.; Spek, A. L. Organometallics 1987, 6, 1202; (b) Haaland, A. Angew. Chem. 1989, 101, 1017; Angew. Chem., Int. Ed. Engl. 1989, 28, 992. 


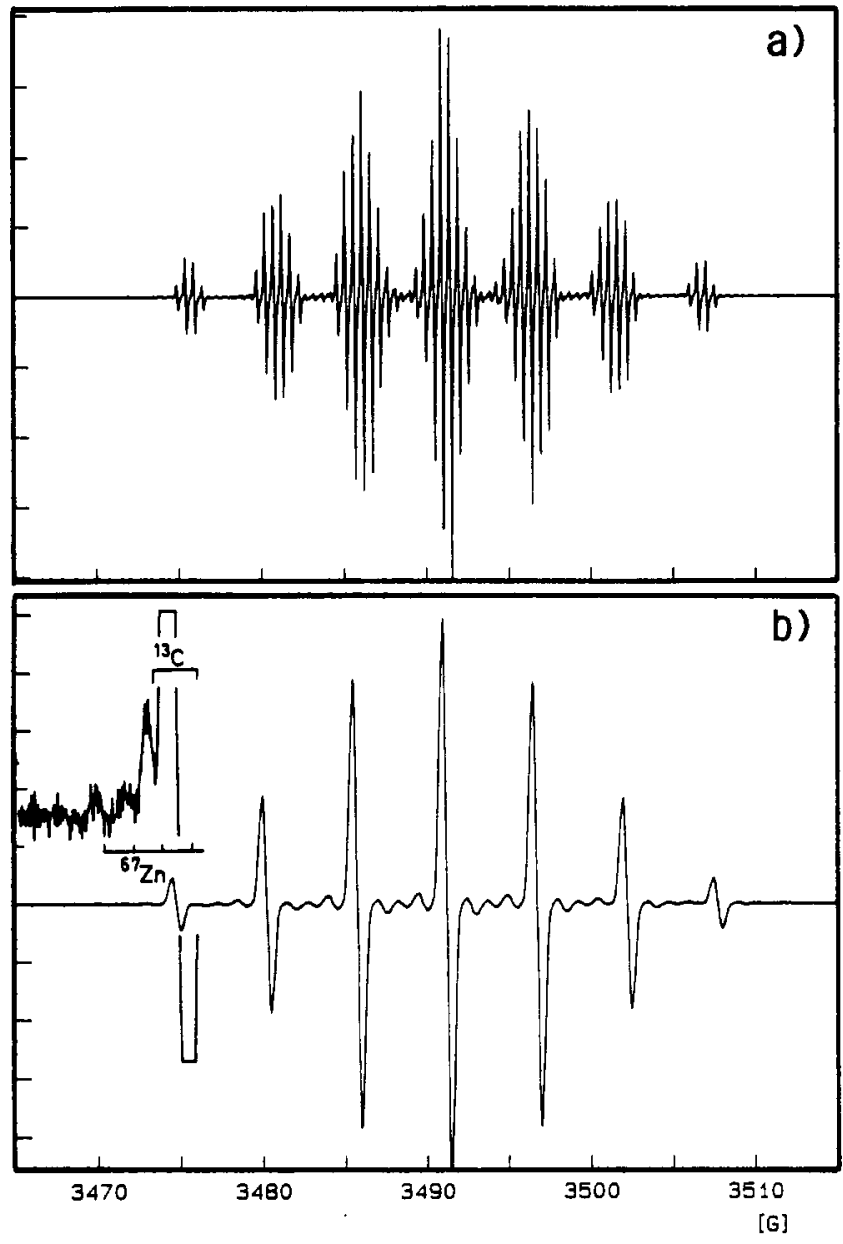

C)

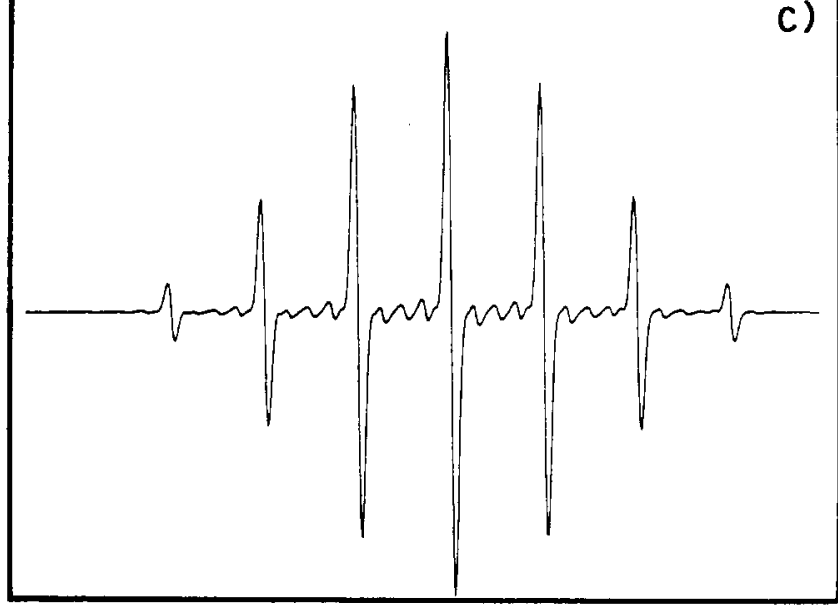

Figure 4. ESR spectra of radical complexes produced thermally from $\mathrm{ZnMe}_{2} \cdot(t-\mathrm{Bu}-\mathrm{DAB})$ (a) in diethyl ether and (b) in THF (an amplified wing section illustrates ${ }^{13} \mathrm{C}$ and ${ }^{67} \mathrm{Zn}$ isotope coupling), and (c) a computer simulated spectrum of (b) with a Gaussian line width of $0.035 \mathrm{mT}$.

ronment of the metal center, notably shorter NM distances. The corresponding zinc and magnesium complexes differ systematically: For $\mathrm{M}=\mathrm{Mg}$ the $\mathrm{CMC}$ angle is generally about 7 to $8^{\circ}$ smaller, the $\mathrm{MC}$ distance about $10 \mathrm{pm}$ longer, and the $\mathrm{MN}$ distances about $10 \mathrm{pm}$ shorter (which leads to slightly larger NMN angles). Keeping in mind that the calculated $\mathrm{ZnC}$ and $\mathrm{ZnN}$ distances most probably give upper bounds to values in the gas phase, ${ }^{3}$ the distances for the MN bonds appear to be quite similar for the two metals, which is consistent with the very similar ionic radii $\left(\mathrm{Zn}, 88 \mathrm{pm} ; \mathrm{Mg}, 86 \mathrm{pm}^{24}\right)$. For the much more covalent $\mathrm{MC}$ bonds in the dialkyl compounds and primary complexes, the

(24) Shannon, R. D. Acta Crystallogr. 1976, A32, 751. smaller covalent radius of zinc $\left(\mathrm{Zn}, 120 \mathrm{pm} ; \mathrm{Mg}, 145 \mathrm{pm}^{25}\right)$ seems to dominate.

The higher deformability of the more ionic $\mathrm{MgC}$ bond $d^{5}$ may be part of the reason for the smaller $\mathrm{CMC}$ angle. Interestingly, the $\mathrm{HMH}$ angle in $\mathrm{MgH}_{2} \cdot \mathrm{DAB}$ is larger than that of the zinc analogue. In all cases the distances within the DAB-M chelate ring are very close to those in the free ligand although in addition to the forced cis conformation (the trans conformation has been found to be the energy minimum for the free ligand) the ring closure also leads to a slight decrease in the $\mathrm{N}=\mathrm{C}-\mathrm{C}$ angle.

The dative character of the bond between the organometallic fragment and the DAB molecule favors an MO description by a correlation diagram. Figure 6 shows the energy change of the localized MOs (the Foster-Boys criterion ${ }^{26}$ has been employed) that is caused by the complex formation $\left(M=Z n, R^{\prime}=M e\right)$. The energies of all DAB MOs are lowered by about 50 mhartrees. Only the shift of the $\mathrm{N}$ lone pairs is slightly higher than 70 mhartrees. The energy of the $\mathrm{CH}$ bonds in the $\mathrm{ZnMe}_{2}$ fragment is raised by about 50 mhartrees and the energy of the $\mathrm{ZnC}$ bonds by about 65 mhartrees. The orbitals of principal quantum number $n=3$ on zinc that have been neglected in this valence-only diagram and center around -2.0 to -2.5 au in the localized picture are lowered by comparable amounts. These long-range interactions support the ionic character of the bonding between the two fragments. The MOs arranged directly around the metal are affected only slightly stronger than all others. When going from $\mathrm{R}^{\prime}=\mathrm{Me}$ to $\mathrm{R}^{\prime}=\mathrm{Et}, i-\mathrm{Pr}$, the energies of the $\mathrm{ZnC}$ and $\mathrm{C}_{\mathrm{Alkyl}} \mathrm{H}$ MOs remain constant. Obviously the localized MO picture does not explain the experimental trends in the transition energies. A change from $\mathbf{M}=\mathrm{Zn}$ to $\mathrm{Mg}$, however, shifts the picture: Now the DAB MOs are lowered by ca. 65 mhartrees and the $\mathrm{N}$ lone pairs by 100 mhartrees, while the MOs of the $\mathrm{MgMe}_{2}$ fragment are raised slightly more than with $\mathrm{M}=\mathrm{Zn}$. The higher positive charge on the metal appears to lead to increased interactions between the two fragments.

The nodal properties of the two highest occupied canonical (nonlocalized) MOs of the primary complexes are depicted in Figure 7a,b. The antisymmetric $\sigma(\mathrm{M}-\mathrm{C})$ combination is the HOMO of the complexes. Both MOs are mainly concentrated in the $\mathrm{CMC}$ region and can be constructed from the corresponding MOs in the dialkyl compounds ${ }^{5}$ by mixing the $\mathrm{p}_{z}$ orbitals. The nonlinearity and the destabilizing electronic interaction with the DAB fragment lead to higher orbital energies than for the corresponding dialkyl compounds (see Table VII). Table VII also shows that the well-known destabilizing hyperconjugative effect of alkyl substitution on carbanionic centers $17,27,28$ holds true for these organometallic complexes (as well as, e.g., for $Z n R^{\prime}{ }_{2}$ ).

Koopmans' theorem ${ }^{29}$ was found to be valid for dimethylzinc; ${ }^{5}$ thus the HOMO energies can be taken as a good approximation of the first ionization potentials for the $\mathrm{Zn}$ complexes and at least the trend for the $\mathrm{Mg}$ complexes should be described correctly.

Some additional information on the bonding in these compounds is given by the Mulliken gross charges. ${ }^{30}$ Table VIII contains a compilation for the primary complexes, their fragments, radical anions, and $T_{1}$ states - the latter two at the optimized geometries of the primary complex ground states. Upon complex formation the density on the metal atoms and the imine carbon and hydrogen atoms is reduced (see Table VIIIa), whereas the density on $\mathbf{N}$ and $\mathrm{H}_{\mathrm{C}}$ increases. This supports a picture not only of a ligand density polarized toward the metal but also of a density shift within the $\mathrm{MR}_{2}$ fragment that is directed away from the chelate ligand. This dipole-dipole-like interaction seems to be a typical feature of the dative bond.

(25) Sutton, L., Ed. Tables of Interatomic Distances and Configurations in Molecules and Ions; Spec. Pubi. Nos. 11 and 18; The Chemical Society of London, 1958 and 1965.

(26) Foster, J. M.; Boys, S. F. Rev. Mod. Phys. 1963, 35, 457.

(27) Hehre, W. J.; Radom, L.; Schleyer, P. v. R.; Pople, J. A. Ab Initio Molecular Orbital Theory; Wiley: New York, 1986

(28) Kollmar, H. J. Am. Chem. Soc. 1978, 100, 2665.

(29) (a) Koopmans, T. Physica 1933, $I, 104$. (b) Smith, D. W.; Day, O. W. J. Chem. Phys, 1975, 62,113.

(30) Mulliken, R. S. J. Chem. Phys. 1955, 23, 1833, 1841, 2338, 2343. 

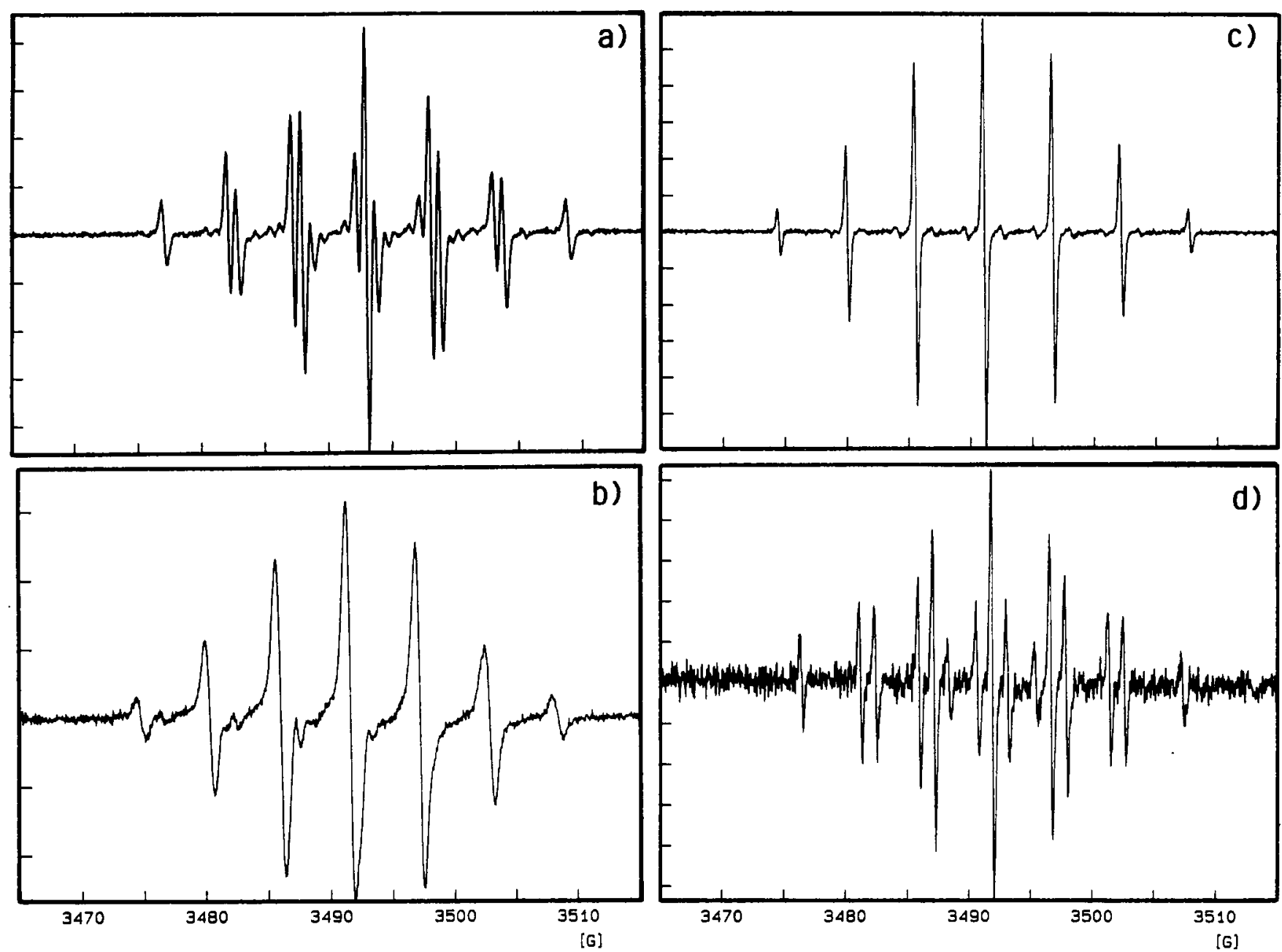

Figure 5. ESR spectra of radical complexes produced thermally from mixing $\mathrm{Zn}(t-\mathrm{Bu})_{2}$ and $t-\mathrm{Bu}-\mathrm{DAB}$ at $300 \mathrm{~K}$ in diethyl ether after $15 \mathrm{~min}$ (a) and $24 \mathrm{~h}$ (b). Radical complexes from $\mathrm{ZnPh}_{2} \cdot(t-\mathrm{Bu}-\mathrm{DAB})(\mathrm{c} \text {, in THF) and } \mathrm{Zn}(0-\mathrm{Xyl}))_{2^{*}}(t-\mathrm{Bu}-\mathrm{DAB})$ (d, in ether) could only be generated photolytically (Table V).

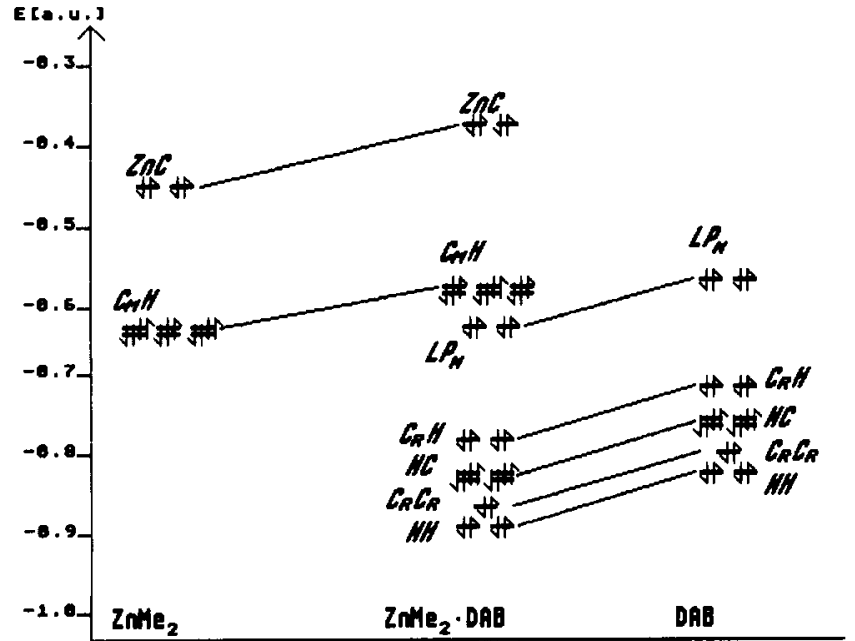

Figure 6. Correlation diagram of localized MOs in $\mathrm{ZnMe} \cdot \mathrm{DAB}$. Bonding electron pairs are labeled by the participating atoms $\left(C_{M}=\right.$ methyl carbon, $C_{R}=$ imine carbon). $L P_{N}$ denotes the lone pairs on the nitrogen atoms. Mixing of NC $\pi$ and $\sigma$ bonding MOs leads to four equivalent $\mathrm{NC}$ bonds.

One way to judge the behavior of the LUMO (which is mostly localized within the chelate ligand, see Figure 7) is to calculate the electron affinities of the complexes. While the absolute values certainly reflect the incomplete basis sets and the neglect of electron correlation, the trends should allow some assessment of factors influencing the energy of the LUMO. The calculated
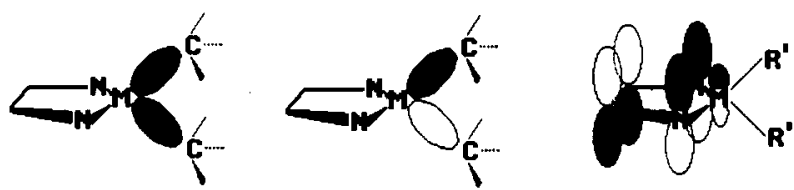

A) CMC-bond (sym)

b) CMC-bond (antisym.,HOMO) C) DAB- $\pi^{*}-M O$ (LUMO)

Figure 7. Schematic representation of the node properties for the primary complex frontier orbitals.

vertical $\triangle S C F$ electron affinities for all and the adiabatic electron affinities for some primary complexes are shown in Table IX (geometries of optimized radical anions are discussed below). The adiabatic electron affinities have been calculated to give a more realistic description of the energy difference between neutral and radical anion species that is studied e.g. by electrochemistry.

The values for the free ligand indicate a strongly unbound anion, a fact that is not changed by inclusion of valence correlation (v.o.p.+ basis, CEPA1). In the series $R^{\prime}=\mathrm{Me}$, Et, $i-\operatorname{Pr}$ the changes are within a narrow range of $0.1 \mathrm{eV}$ and the relative order is even reversed for the adiabatic EA. In contrast to the few experimental data, ${ }^{4}$ the $\mathrm{Mg}$ complexes exhibit consistently higher electron affinities by ca. $0.45 \mathrm{eV}$, which is in agreement with the ionic bonding picture discussed above and in ref 31 . The discrepancy with respect to some electrochemical data ${ }^{4}$ may be due either to the neglect of electron correlation in the calculations or to the effects of solvation.

(31) Fischer-Hjalmars, I.; Henriksson-Enflo, A. Adv. Quant. Chem. 1982, 
Table VI. Internal Coordinates of Various Primary Complexes<smiles>CC1=NN(Cl)N(C(C)(C)C(C)(C)Cl)N1C(C)(C)C(C)(C)C</smiles>

Distances (pm)

\begin{tabular}{|c|c|c|c|c|c|c|c|c|}
\hline species & $\begin{array}{l}\mathrm{MC}_{1} \\
\mathrm{MC}_{2}\end{array}$ & $\begin{array}{l}\mathbf{M N}_{1} \\
\mathbf{M N}_{2}\end{array}$ & $\begin{array}{l}\mathrm{N}_{1} \mathrm{C}_{3} \\
\mathrm{~N}_{2} \mathrm{C}_{4}\end{array}$ & $\mathrm{C}_{3} \mathrm{C}_{4}$ & $\begin{array}{l}\mathrm{C}_{1} \mathrm{C}_{5} \\
\mathrm{C}_{2} \mathrm{C}_{6}\end{array}$ & $\begin{array}{l}\mathrm{N}_{1} \mathrm{C}_{7} \\
\mathrm{~N}_{2} \mathrm{C}_{8}\end{array}$ & $\begin{array}{l}\mathrm{MH}_{1} \\
\mathrm{MH}_{2}\end{array}$ & $\mathrm{CF}$ \\
\hline $\begin{array}{l}Z n M e_{2} \cdot(t-B u-D A B) \\
\exp .^{a}\end{array}$ & $\begin{array}{l}201.0(7) \\
199.5(7)\end{array}$ & $\begin{array}{l}222.5(7) \\
220.7(7)\end{array}$ & $\begin{array}{l}124(l) \\
125(l)\end{array}$ & $148(1)$ & & $\begin{array}{l}146(l) \\
148(l)\end{array}$ & & \\
\hline 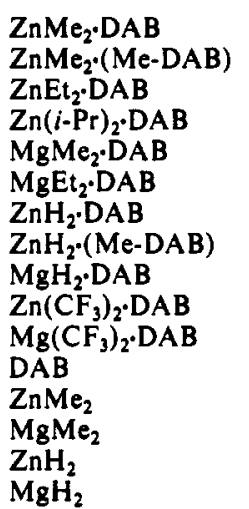 & $\begin{array}{l}203 \\
203 \\
203 \\
203 \\
213 \\
214\end{array}$ & $\begin{array}{l}233 \\
233 \\
235 \\
234 \\
226 \\
225 \\
226 \\
226 \\
221 \\
218 \\
217\end{array}$ & $\begin{array}{l}125 \\
125 \\
126 \\
126 \\
126 \\
126 \\
125 \\
125 \\
125 \\
125 \\
126 \\
126\end{array}$ & $\begin{array}{l}147 \\
146 \\
149 \\
149 \\
147 \\
148 \\
149 \\
147 \\
147 \\
148 \\
147 \\
147\end{array}$ & $\begin{array}{l}153 \\
154 \\
153\end{array}$ & 145 & $\begin{array}{l}163 \\
164 \\
174\end{array}$ & $\begin{array}{l}138 \\
138\end{array}$ \\
\hline
\end{tabular}

Angles (deg)

\begin{tabular}{|c|c|c|c|c|c|}
\hline species & $\mathrm{C}_{1} \mathrm{MC}_{2}$ & $\mathrm{~N}_{1} \mathrm{MN}_{2}$ & $\begin{array}{l}\mathrm{MN}_{1} \mathrm{C}_{3} \\
\mathrm{MN}_{2} \mathrm{C}_{4}\end{array}$ & $\begin{array}{l}\mathrm{N}_{1} \mathrm{C}_{3} \mathrm{C}_{4} \\
\mathrm{~N}_{2} \mathrm{C}_{4} \mathrm{C}_{3}\end{array}$ & $\mathrm{HMH}$ \\
\hline $\begin{array}{l}Z n M e_{2} \cdot(t-B u-D A B) \\
\exp .^{a}\end{array}$ & $137.3(3)$ & $75.0(2)$ & $\begin{array}{l}112.8(6) \\
112.9(6)\end{array}$ & $\begin{array}{l}119.1(9) \\
119.8(8)\end{array}$ & \\
\hline $\begin{array}{l}\mathrm{ZnMe}_{2} \cdot \mathrm{DAB} \\
\mathrm{ZnMe} \mathrm{C}_{2} \cdot(\mathrm{Me}-\mathrm{DAB}) \\
\mathrm{ZnEt} \mathrm{2}_{2} \cdot \mathrm{DAB} \\
\mathrm{Zn}(i \cdot \mathrm{Pr})_{2} \cdot \mathrm{DAB} \\
\mathrm{MgMe}_{2} \cdot \mathrm{DAB} \\
\mathrm{MgEt}_{2} \cdot \mathrm{DAB} \\
\mathrm{ZnH}_{2} \cdot \mathrm{DAB} \\
\mathrm{ZnH}_{2} \cdot(\mathrm{Me}-\mathrm{DAB}) \\
\mathrm{MgH}_{2} \cdot \mathrm{DAB} \\
\mathrm{Zn}\left(\mathrm{CF}_{3}\right)_{2} \cdot \mathrm{DAB} \\
\mathrm{Mg}\left(\mathrm{CF}_{3}\right)_{2} \cdot \mathrm{DAB} \\
\mathrm{DAB}\end{array}$ & $\begin{array}{l}137 \\
136 \\
138 \\
140 \\
132 \\
131\end{array}$ & $\begin{array}{l}70 \\
71 \\
70 \\
70 \\
73 \\
73 \\
72 \\
73 \\
73 \\
75 \\
76\end{array}$ & $\begin{array}{l}117 \\
115 \\
117 \\
117 \\
115 \\
115 \\
116 \\
114 \\
116 \\
113 \\
113\end{array}$ & $\begin{array}{l}118 \\
120 \\
119 \\
118 \\
118 \\
118 \\
118 \\
119 \\
118 \\
119 \\
119 \\
120\end{array}$ & $\begin{array}{l}145 \\
144 \\
149\end{array}$ \\
\hline
\end{tabular}

${ }^{a}$ For pairs of coordinates that are equivalent by symmetry in the calculation, both values are listed for the experimental structure. Note that the numbering is different from that adopted in the representation of the crystal structure (cf. Figure 1 ).

Table VII. Energies of the Two Highest Occupied MOs of Some Primary Complexes and $\mathrm{MR}_{2}$ Compounds (au)

\begin{tabular}{|c|c|c|c|c|c|}
\hline species & $\epsilon_{a 3}$ & $\epsilon_{\mathrm{g}}$ & species & $\epsilon_{\mathrm{as}}$ & $\epsilon_{3}$ \\
\hline $\begin{array}{l}\mathrm{ZnMe}_{2} \cdot \mathrm{DAB} \\
\mathrm{ZnMe} \mathrm{Me}_{2} \cdot(\mathrm{Me}-\mathrm{DAB}) \\
\mathrm{ZnEt} \cdot \mathrm{DAB} \\
\mathrm{Zn}(i-\mathrm{Pr})_{2} \cdot \mathrm{DAB} \\
\mathrm{MgMe}_{2} \cdot \mathrm{DAB} \\
\mathrm{MgEt}_{2} \cdot \mathrm{DAB} \\
\mathrm{ZnMe}_{2} \\
\mathrm{ZnEt}_{2} \\
\mathrm{MgMe}_{2}\end{array}$ & $\begin{array}{l}-0.285 \\
-0.283 \\
-0.270 \\
-0.259 \\
-0.270 \\
-0.261 \\
-0.347 \\
-0.311 \\
-0.339\end{array}$ & $\begin{array}{l}-0.344 \\
-0.342 \\
-0.325 \\
-0.315 \\
-0.314 \\
-0.297 \\
-0.428 \\
-0.388 \\
-0.391\end{array}$ & $\begin{array}{l}\mathrm{Zn}\left(\mathrm{CF}_{3}\right)_{2} \cdot \mathrm{DAB} \\
\mathrm{Mg}\left(\mathrm{CF}_{3}\right)_{2} \cdot \mathrm{DAB} \\
\mathrm{ZnH} \mathrm{H}_{2} \cdot \mathrm{DAB} \\
\mathrm{ZnH}_{2} \cdot(\mathrm{Me}-\mathrm{DAB}) \\
\mathrm{MgH}_{2} \cdot \mathrm{DAB} \\
\mathrm{ZnH}_{2} \\
\mathrm{MgH}_{2}\end{array}$ & $\begin{array}{l}-0.407 \\
-0.401 \\
-0.309 \\
-0.307 \\
-0.303 \\
-0.387 \\
-0.373\end{array}$ & $\begin{array}{l}-0.449 \\
-0.433 \\
-0.360 \\
-0.356 \\
-0.335 \\
-0.471 \\
-0.425\end{array}$ \\
\hline
\end{tabular}

In agreement with the small change in the EA, the Mulliken atomic gross charges (see Table VIII) confirm that a change in the alkyl groups on the metal has a minor influence on the DAB fragment (except for $\mathrm{R}^{\prime}=\mathrm{CF}_{3}$ which is discussed below). The stronger polarization of the DAB ligand for the complexes with $\mathbf{M}=\mathbf{M g}$ is also documented by the charges.

The wavelengths of the vertical $S_{0} \rightarrow T_{1}$ and $S_{0} \rightarrow S_{1}$ LLCT transitions $\sigma(\mathrm{M}-\mathrm{C}) \rightarrow \pi^{*}{ }_{\mathrm{DAB}}$ are summarized in Table IX. The orbital representations in Figure 7 show that the HOMO and LUMO belong to the same symmetry species and that their spatial orientation is favorable for an interaction. Presumably, the $S_{0}$ $\rightarrow S_{1}$ transition is responsible for the intense LLCT visual $a b$ sorption band of many primary complexes, the $S_{0} \rightarrow T_{1}$ transition being spin forbidden. Considering that the experimental wavelengths correspond to the absorption maxima measured in solution for the $N, N^{\prime}$-di-tert-butyl-substituted complexes ${ }^{2 f}$ and that the calculations do not include correlation effects or zero-point vibrational corrections, the agreement is quite satisfactory.

From the discussion above it is clear that the destabilizing hyperconjugative influence of methyl groups at the carbanionic centers on the HOMO is responsible for the observed trends in the series $\mathrm{R}^{\prime}=\mathrm{Me}$, Et, $i$-Pr, $t$-Bu. Neither the LUMO energies nor the slightly changed geometries have a significant effect. As Figure 8 shows, an increase in the CMC angle would even lead to an increase in the transition energy; the angle was varied starting from the optimized ground-state geometry. 
Table VIII. Mulliken Charges of Primary Complexes, Fragments, Radical Anions, and Excited Triplet States ${ }^{a}$

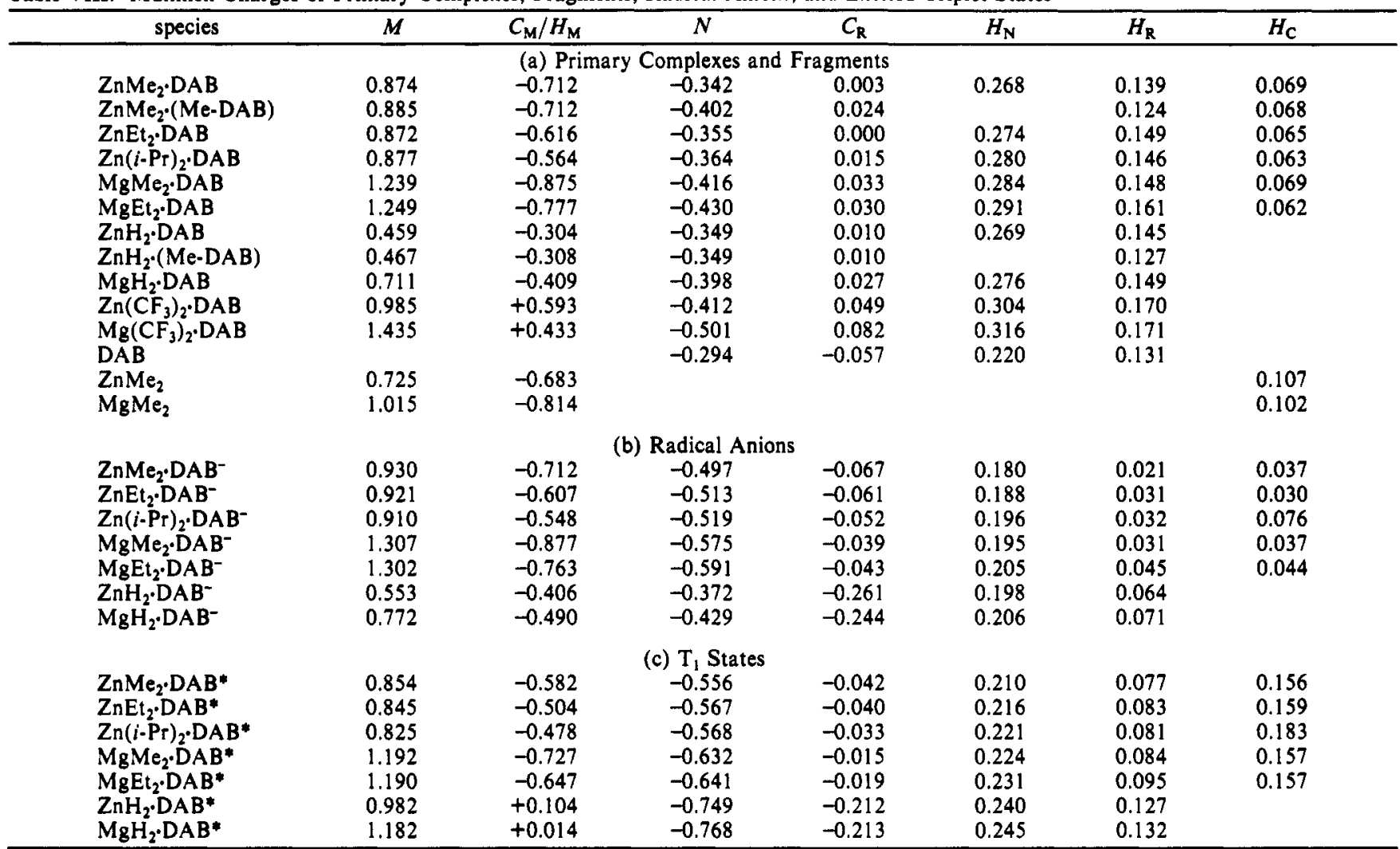

'The index $M$ denotes the carbanionic carbon atoms (or the hydridic hydrogen atoms for $\mathrm{R}^{\prime}=\mathrm{H}$ ), the index $R$ stands for imine carbon and hydrogen atoms, and $H_{\mathrm{N}}$ and $H_{\mathrm{C}}$ are the hydrogen atoms bound to nitrogen or the carbanionic carbon, respectively (for the latter an average charge is given).

Table IX. Electron Affinities and LLCT Wavelengths for the Primary Complexes

\begin{tabular}{|c|c|c|c|c|c|}
\hline \multirow[b]{2}{*}{ species } & \multicolumn{2}{|c|}{$\begin{array}{c}\text { electron } \\
\text { affinities, } \mathrm{eV}\end{array}$} & \multicolumn{2}{|c|}{$\lambda(\mathrm{LLCT}), \mathrm{nm}$} & \multirow[b]{2}{*}{$\exp .^{a}$} \\
\hline & $\Delta E_{\text {vertical }}$ & $\Delta E_{\text {opt }}$ & $S_{0} \rightarrow T_{1}$ & $\mathbf{S}_{0} \rightarrow \mathbf{S}_{1}$ & \\
\hline $\begin{array}{l}\mathrm{ZnMe}_{2} \cdot \mathrm{DAB} \\
\mathrm{ZnMe}_{2} \cdot(\mathrm{Me}-\mathrm{DAB}) \\
\mathrm{ZnEt} \cdot \mathrm{DAB}_{2} \cdot \mathrm{DAB} \\
\mathrm{Zn}(i \cdot \mathrm{Pr})_{2} \cdot \mathrm{DAB} \\
\mathrm{MgMe}_{2} \cdot \mathrm{DAB} \\
\mathrm{MgEt}_{2} \cdot \mathrm{DAB} \\
\mathrm{ZnH}_{2} \cdot \mathrm{DAB} \\
\mathrm{ZnH}_{2} \cdot(\mathrm{Me}-\mathrm{DAB}) \\
\mathrm{MgH}_{2} \cdot \mathrm{DAB} \\
\mathrm{Zn}\left(\mathrm{CF}_{3}\right)_{2} \cdot \mathrm{DAB} \\
\mathrm{Mg}\left(\mathrm{CF}_{3}\right)_{2} \cdot \mathrm{DAB} \\
\mathrm{DAB}\end{array}$ & $\begin{array}{r}0.096 \\
-0.100 \\
0.156 \\
0.234 \\
0.531 \\
0.595 \\
0.023 \\
-0.201 \\
0.290 \\
1.242 \\
1.570 \\
-1.467\end{array}$ & $\begin{array}{l}0.773 \\
0.735 \\
1.269\end{array}$ & $\begin{array}{l}457 \\
419 \\
545 \\
646 \\
614 \\
765 \\
352 \\
329 \\
399 \\
264 \\
287\end{array}$ & $\begin{array}{l}418 \\
389 \\
491 \\
542 \\
656 \\
324 \\
304 \\
358\end{array}$ & $\begin{array}{l}400^{b} \\
400^{b} \\
490 \\
590\end{array}$ \\
\hline
\end{tabular}

"The experimental wavelengths correspond to the position of the extinction maxima for complexes with the $t$-Bu-DAB ligand. 2 ' $b$ For $R^{\prime}$ = Me solvent effects have been studied. In THF the maximum was found at $381 \mathrm{~nm}$, for nonpolar solvents (hexane, benzene) at $388 \mathrm{~nm}$ (cf. Table V).

(b) Geometries of Radical Anions and the Lowest Excited States of $\mathbf{M R}_{2}{ }_{2} \cdot \mathbf{D A B}$. The most important internal coordinates of the optimized radical anions and $T_{1}$ states with $R^{\prime}=M e$ as well as for the free DAB radical anion are summarized in Table $X$. For

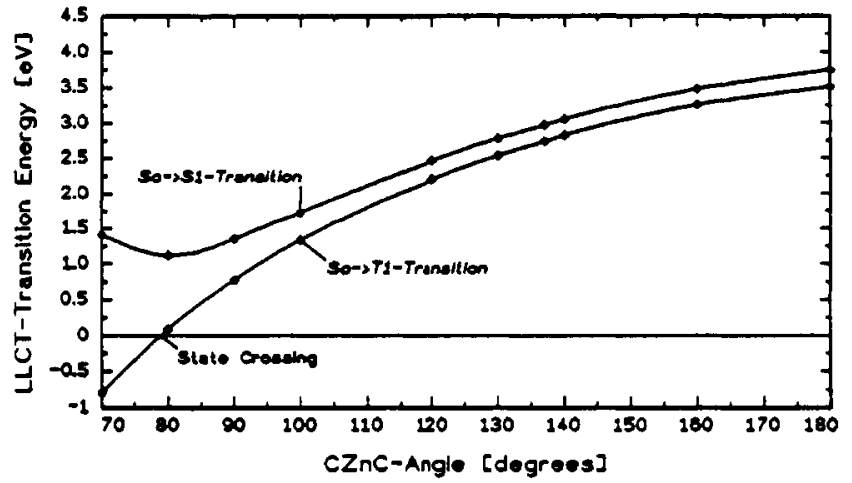

Figure 8. The $C Z_{n} C$ angle dependency of the $S_{0} \rightarrow T_{1}$ and $S_{0} \rightarrow S_{1}$ transition energies in $\mathrm{ZnMe}_{2} \cdot \mathrm{DAB}$.

the radical anions the MC distances are significantly longer (7-8 $\mathrm{pm}$ ) than for the neutral primary complexes; the $\mathrm{MN}$ distances are ca. 12-15 pm shorter, the $\mathrm{NC}_{\text {IMINE }}$ distances ca. 5-6 pm longer, and the $C_{\text {IMINE }} C_{\text {IMINE }}$ distances ca. 8-9 pm shorter. The CMC angles are smaller by about $9^{\circ}$, and the angles within the chelate ring are also slightly different.

These changes can be understood easily when the character of the SOMO (the LUMO in the neutral species, see Figure 7) is considered. In addition to the plane of the chelate ring there exists

Table X. Internal Coordinates of Some Radical Anion and $T_{1}$ Species

\begin{tabular}{|c|c|c|c|c|c|c|c|c|}
\hline \multirow[b]{2}{*}{ species } & \multicolumn{4}{|c|}{ distances, pm } & \multicolumn{4}{|c|}{ angles, deg } \\
\hline & $\overline{\mathrm{MC}_{1}}$ & $\mathbf{M N}_{1}$ & $\mathrm{~N}_{1} \mathrm{C}_{3}$ & $\mathrm{C}_{2} \mathrm{C}_{3}$ & $\mathrm{C}_{1} \mathrm{MC}_{2}$ & $\mathrm{~N}_{1} \mathrm{MN}_{2}$ & $\mathrm{MN}_{1} \mathrm{C}_{3}$ & $\mathrm{~N}_{1} \mathrm{C}_{3} \mathrm{C}_{4}$ \\
\hline $\begin{array}{l}\mathrm{ZnMe}_{2} \cdot \mathrm{DAB}^{-} \\
\mathrm{ZnEt}_{2} \cdot \mathrm{DAB}^{-} \\
\mathrm{MgMe}_{2} \cdot \mathrm{DAB}^{-} \\
\mathrm{DAB}^{-} \\
\mathrm{ZnMe}_{2} \cdot \mathrm{DAB}\left(\mathrm{T}_{1}\right) \\
\mathrm{MgMe}_{2} \cdot \mathrm{DAB}\left(\mathrm{T}_{1}\right)\end{array}$ & $\begin{array}{l}210 \\
210 \\
221 \\
222 \\
228\end{array}$ & $\begin{array}{l}218 \\
217 \\
214 \\
\\
208 \\
204 \\
\end{array}$ & $\begin{array}{l}132 \\
132 \\
132 \\
132 \\
132 \\
133\end{array}$ & $\begin{array}{l}140 \\
140 \\
139 \\
140 \\
139 \\
139\end{array}$ & $\begin{array}{l}127 \\
128 \\
124 \\
\\
89 \\
87\end{array}$ & $\begin{array}{l}76 \\
77 \\
78 \\
79 \\
81\end{array}$ & $\begin{array}{l}112 \\
112 \\
112 \\
112 \\
111\end{array}$ & $\begin{array}{l}120 \\
119 \\
119 \\
123 \\
118 \\
119\end{array}$ \\
\hline
\end{tabular}


a nodal plane that separates the imine carbon centers from the nitrogen atoms whereas there is no nodal plane between the two imine carbons and between nitrogen and metal atoms. The occupation of this MO by one electron therefore leads to the observed geometry change within the DAB ligand which also occurs in the free ligand (Table $X$ ). The most important effect is the shortening of the MN bonds which in turn is connected to a weakening of the $\mathrm{MC}$ bond and the related decrease in the CMC angle. These results agree with the observation of Krishnan et al ${ }^{32}$ that the reduction of $2,2^{\prime}$-bipyridine leads to an increase in the basicity of the ligand by several orders of magnitude.

For the $T_{1}$ states the $C M C$ angle even decreases to values below $90^{\circ}$ and the $\mathrm{MC}$ bonds are lengthened by more than $15 \mathrm{pm}$. The MN distance is still considerably shorter than that for the radical anion because, in addition to the effects of populating the LUMO, the removal of an electron in the CMC region and the related weakening of the $\mathrm{MC}$ bond allow the NM bond to strengthen considerably in this LLCT excited state.

As Figure 8 shows, at smaller CMC angles there is a crossing between the $T_{1}$ and $S_{0}$ hypersurfaces. This possibility of a crossing between the two states allows a large nuclear relaxation of the excited state as compared to the ground state. The calculated energy differences between the minima of the two hypersurfaces are only 0.75 and $0.51 \mathrm{eV}$ for $\mathrm{M}=\mathrm{Zn}, \mathrm{Mg}$, respectively, corresponding to expected phosphorescence wavelengths in the IR region.

For the $S_{1}$ states of $\mathrm{MMe}_{2} \cdot \mathrm{DAB}$ no complete geometry optimization for the corresponding MCSCF wave function has been possible. Assuming that the DAB-M ring geometry is not too different for the $S_{1}$ and $T_{1}$ states, the $C M C$ angle in $\mathrm{ZnMe}_{2} \cdot \mathrm{DAB}$ was varied independently, starting from the optimized $T_{1}$ geometry (see Table X), and an angle of ca. $120^{\circ}$ was found. It seems that, in spite of the forbidden $S_{0}-S_{1}$ crossing (an avoided crossing can be anticipated from Figure 8 ), there is still a significant nuclear relaxation for the $S_{0} \rightarrow S_{1}$ transition-in agreement with LLCT band widths of about $9500 \mathrm{~cm}^{-1}$ at half-height (cf. Figure 2) and with the relatively large Franck-Condon factors deduced from spectroscopic and cyclovoltammetric data for $2,2^{\prime}$-bipyridine complexes. ${ }^{4}$ The energy difference of ca. $2.2 \mathrm{eV}$ between the partially optimized $S_{1}$ state and the optimized $S_{0}$ state corresponds to a wavelength of $570 \mathrm{~nm}$ as compared to $600-650 \mathrm{~nm}$ for the low energy end of the absorption band of $\mathrm{ZnMe}_{2} \cdot(t-\mathrm{Bu}-\mathrm{DAB})$. This indicates that the partially optimized structure is already relatively close to the minimum of the $S_{1}$ hypersurface.

The comparison of the Mulliken charges for ground states, anions, and $T_{1}$ states as taken from Table VIII discloses a very interesting feature: The dipole-dipole-like density shift which marks the dative NM bond in the primary complexes is preserved in the anions, leading to an even higher positive charge on the metal and an additional density shift toward the alkyl hydrogen atoms. For the $T_{1}$ states, however, the charge on the metal decreases while the density on nitrogen is even higher than in the anions, although an electron has been removed from the CMC region. Apparently the borderline to covalent bonding is crossed for the $T_{1}$ states (for the situation in the radicals and the alkylation products see below). Nuclear relaxation leads to an even higher density on nitrogen, while the charge on the metal and the density on the alkyl hydrogens show a slight increase.

The calculated dipole moments (see Table XI) support the LLCT character of the transitions and agree with a hypsochromic effect in polar solvents. The values for the neutral ground-state species indicate a small increase of the dipole moment in the order $\mathrm{R}^{\prime}=\mathrm{Me}, \mathrm{Et}, \boldsymbol{i}-\mathrm{Pr}$; the higher dipole moment of the magnesium compounds for a given $R^{\prime}$ is much more obvious. As expected, the reduction and particularly the LLCT transition shift considerable amounts of charge toward the DAB ligand. The nuclear relaxation of the anions and excited states reduces this effect.

(c) The Effect of Alkyl Substitution on Nitrogen. To get a feeling for the magnitude of effects that the experimentally om-

(32) Krishnan, C. V.; Creutz, C.; Schwarz, H. A.; Sutin, N. J. Am. Chem. Soc. $1983,105,5617$
Table XI. Dipole Moments (D) of Primary Complexes, Anions, and Excited States ${ }^{a}$

\begin{tabular}{|c|c|c|c|c|c|}
\hline species & $S_{0}$ & anion $^{b}$ & $T_{1}$ & $S_{1}{ }^{c}$ & $\left|\mu_{S_{0}}\right|-\left|\mu_{T_{1}}\right|$ \\
\hline $\begin{array}{l}\mathrm{ZnMe}_{2} \cdot \mathrm{DAB} \\
\mathrm{ZnMe}_{2} \cdot(\mathrm{Me}-\mathrm{DAB})\end{array}$ & $\begin{array}{l}-9.145 \\
-8.660\end{array}$ & -0.284 & 2.164 & 3.028 & 6.981 \\
\hline $\begin{array}{l}\mathrm{ZnEt} t_{2} \cdot \mathrm{DAB} \\
\mathrm{Zn}(i-\mathrm{Pr})_{2} \cdot \mathrm{DAB}\end{array}$ & $\begin{array}{l}-9.329 \\
-9.618\end{array}$ & $\begin{array}{l}-0.177 \\
-0.135\end{array}$ & $\begin{array}{l}2.310 \\
2.083\end{array}$ & 3.098 & $\begin{array}{l}7.019 \\
7.535\end{array}$ \\
\hline $\mathrm{MgMe}_{2} \cdot \mathrm{DAB}$ & -10.580 & -0.684 & 0.999 & 1.490 & 9.581 \\
\hline $\mathrm{MgEt}_{2} \cdot \mathrm{DAB}$ & -10.939 & -0.550 & 1.126 & 1.459 & 9.813 \\
\hline $\begin{array}{l}\mathrm{ZnH}_{2} \cdot \mathrm{DAB} \\
\mathrm{ZnH} \cdot(\mathrm{Me}-\mathrm{DAB})\end{array}$ & $\begin{array}{l}-8.773 \\
-8.224\end{array}$ & -0.393 & 0.990 & 2.049 & 7.783 \\
\hline $\begin{array}{l}\mathrm{MgH} H_{2} \cdot \mathrm{DAB} \\
\mathrm{Zn}\left(\mathrm{CF}_{3}\right)_{2} \cdot \mathrm{DAB} \\
\mathrm{Mg}\left(\mathrm{CF}_{3}\right)_{2} \cdot \mathrm{DAB}\end{array}$ & $\begin{array}{r}-9.120 \\
-13.240 \\
-14.189\end{array}$ & -0.706 & 1.037 & 1.450 & 8.083 \\
\hline $\begin{array}{l}\text { optimized open-shell } \\
\mathrm{ZnMe}_{2} \cdot \mathrm{DAB}^{-b} \\
\mathrm{ZnEt}_{2} \cdot \mathrm{DAB}^{-b} \\
\mathrm{MgMe}_{2} \cdot \mathrm{DAB}^{-b}\end{array}$ & & $\begin{array}{l}-4.946 \\
-3.852 \\
-7.192\end{array}$ & & & \\
\hline $\begin{array}{l}\mathrm{ZnMe}_{2} \cdot \operatorname{DAB}\left(\mathrm{T}_{1}\right) \\
\mathrm{MgMe}_{2} \cdot \mathrm{DAB}\left(\mathrm{T}_{1}\right)\end{array}$ & & & $\begin{array}{l}-1.597 \\
-2.651\end{array}$ & & $\begin{array}{l}7.548 \\
7.931\end{array}$ \\
\hline
\end{tabular}

${ }^{a}$ Due to the symmetry restrictions, there are only dipole moment components in the $z$ direction. A minus sign indicates that the dipole moment vector is directed toward the organometallic fragment. $b$ The center of gravity was chosen as a gauge for the anion dipole moments. 'The $S_{1}$ values were taken from MCSCF calculations and therefore should not be directly compared to the other values, which were obtained from $\mathrm{HF}$ calculations.

nipresent alkyl substituents on nitrogen exert on the properties of the primary complexes, the two complexes $\mathrm{ZnH}_{2} \cdot(\mathrm{Me}-\mathrm{DAB})$ and $\mathrm{ZnMe}_{2} \cdot(\mathrm{Me}-\mathrm{DAB})$ have been optimized (see Table VI). Obviously the effect of the two methyl groups on the geometry is very small; tert-butyl groups, of course, might behave slightly different.

The destabilizing influence of the alkyl groups on the energies of the highest occupied MOs is below $5 \mathrm{mH}(=0.14 \mathrm{eV}$ ) (see Table VII), whereas the also destabilizing effect on the LUMO leads to negative electron affinities (at the given level of theory) and LLCT transition energies about $0.25 \mathrm{eV}$ higher than for $\mathrm{R}=\mathrm{H}$. This brings the transition wavelengths (see Table IX) into even better agreement with the experimental data for $\mathrm{ZnMe}_{2} \cdot(t-\mathrm{Bu}$ DAB). The Mulliken charges and dipole moments (see Tables VIII and XI) also support the slight increase of electron density in the ligand region.

(d) Primary Chelate Complexes with $\mathbf{R}^{\prime}=\mathbf{C F}_{3}$. To stake out the range of variation in the properties of the primary complexes, which can be effected by choice of very electronegative alkyl substituents ( $\left.R^{\prime}\right)$ on the metal, the (experimentally still unknown) complexes $\mathrm{M}\left(\mathrm{CF}_{3}\right)_{2}$. DAB have also been included in the study. Comparison of the geometries with those of complexes $\mathrm{MMe}_{2}$. DAB (see Table VI) indicates the strong effect of the $\mathrm{CF}_{3}$ groups. While the MC distances are only slightly longer, the $C M C$ angles are smaller by 9 and $7^{\circ}$ and the MN distances shorter by 15 and $9 \mathrm{pm}$ for $\mathrm{M}=\mathrm{Zn}$ and $\mathrm{Mg}$, respectively. The higher Lewis acidity of the organometallic fragment obviously leads to a much stronger interaction between the two fragments.

The strongly positive electron affinities (see Table IX), the Mulliken charges (see Table VIII), and the dipole moments (see Table XI) document the charge withdrawal from the ligand, permitting an easy reduction of these still unknown compounds. The stabilizing effect on the highest occupied MOs (see Table VII) outweighs the effect on the LUMO so that the $S_{0} \rightarrow T_{1}$ transitions are shifted into the near-UV region (see Table IX). MCSCF calculations for the $S_{0} \rightarrow S_{1}$ transitions have not been possible, but from the previous examples one can expect the absorption bands around $250 \mathrm{~nm}$, probably leading to colorless compounds. A decomposition through an SET mechanism thus appears less likely for $\mathrm{R}^{\prime}=\mathrm{CF}_{3}$ than for $\mathrm{R}^{\prime}=\mathrm{Me}, \mathrm{Et}, i-\mathrm{Pr}, t-\mathrm{Bu}$.

(e) The Radicals MMe-DAB. The optimized geometries of the radicals (see Table XII) yield important information on the electronic structure of these species. The geometry of the DAB fragment is very close to that of the optimized radical anions or $T_{1}$ states (see Table $X$ ) and the $M N$ distances are up to $30 \mathrm{pm}$ 


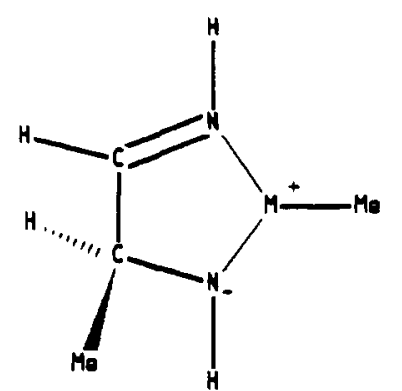

a c-alkylation products

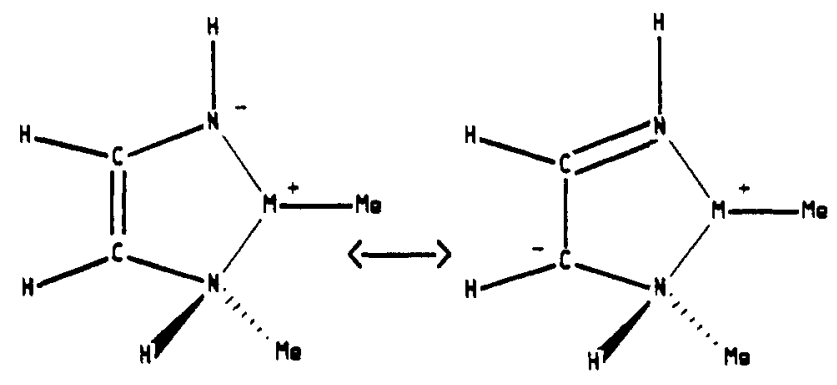

b) $\mathbf{N}$-alkylation products

Figure 9. Valence bond structures for the alkylation products.

Table XII. Internal Coordinates of the Radicals MMe.DAB

\begin{tabular}{ccc} 
& \\
& & \\
& $M=\mathrm{Zn}$ & $\mathrm{M}=\mathrm{Mg}$ \\
\hline & Distances, pm & \\
$\mathrm{MC}_{1}$ & 197 & 202 \\
$\mathrm{MN}_{1} \mathrm{C}_{2}$ & 198 & 197 \\
$\mathrm{C}_{2} \mathrm{C}_{3}$ & 132 & 132 \\
& 141 & 141 \\
$\mathrm{~N}_{1} \mathrm{MN}_{2}$ & Angles, deg & 84 \\
$\mathrm{MN}_{1} \mathrm{C}_{2}$ & 83 & 110 \\
$\mathrm{~N}_{1} \mathrm{C}_{2} \mathrm{C}_{3}$ & 111 & 118 \\
\hline
\end{tabular}

Table XIII. Mulliken Charges of the MMe.DAB Radicals ${ }^{a}$

\begin{tabular}{cccccccc}
\hline $\mathrm{M}$ & $M$ & $C_{\mathrm{M}}$ & $C_{\mathrm{R}}$ & $N$ & $H_{\mathrm{C}}$ & $H_{\mathrm{R}}$ & $H_{\mathrm{N}}$ \\
\hline $\mathrm{Zn}$ & 1.033 & -0.698 & -0.017 & -0.645 & 0.097 & 0.116 & 0.248 \\
$\mathrm{Mg}$ & 1.357 & -0.872 & +0.004 & -0.758 & 0.093 & 0.118 & 0.255 \\
\hline
\end{tabular}

${ }^{a}$ For an explanation of indices see Table VIII.

shorter than those for the primary complexes (see Table VI), i.e. a description as $\mathrm{DAB}^{\circ-}$ is appropriate. On the other hand, the $\mathrm{MC}$ distances in the MMe.DAB radicals are much shorter than those for the radicals $\mathrm{MMe}$ and closer to the values for the dimethyl compounds ${ }^{5,33}$ or, at least for $\mathrm{M}=\mathrm{Zn},{ }^{34}$ to the methyl cations $\mathrm{MMe}^{+}$. Thus, a formulation as $\left(\mathrm{MMe}^{+}\right) \cdot\left(\mathrm{DAB}^{\circ-}\right)$ seems appropriate. The high charges on metal and nitrogen support this bonding picture (see Table XIII). Consequently, for $\mathrm{M}=\mathrm{Zn}$ these radicals are also formed in the reaction between $M^{+} D^{-} B^{--}$ $\left(\mathrm{M}=\mathrm{Li}, \mathrm{Na}\right.$, etc.) and $\mathrm{R}^{\prime} \mathrm{ZnCl}$. ${ }^{2 \mathrm{e}}$

However, the much more covalent character of the $\mathrm{MN}$ bond in the radical complex as compared to that in the primary complexes or, for example, the $\mathrm{M}^{+} \mathrm{DAB}{ }^{--}$compounds $(\mathrm{M}=$ alkali metal) is documented by the very short distances. The canonical MOs also agree with this picture of bonding. As for the radical anions discussed above, the SOMO corresponds to the $\pi^{*} \mathrm{MO}$ of DAB.

Recently ${ }^{35}$ the ionization potentials of the radical complexes $\mathrm{ZnMe} \cdot(t-\mathrm{Bu}-\mathrm{DAB}), \mathrm{ZnEt} \cdot(t-\mathrm{Bu}-\mathrm{DAB})$, and $\mathrm{AlMe} \mathrm{M}_{2} \cdot(t-\mathrm{Bu}-\mathrm{DAB})$ have been measured and discussed via MNDO calculations. It is worthwhile to see how the present calculations compare with these data. Louwen et al. observed that the experimental first ionization potential of the organoaluminum radical (which is

(33) (a) Almenningen, A.; Helgaker, T. U.; Haaland, A.; Samdal, S. Acta Chem. Scand. Ser. A 1982, A36, 159. (b) Barandiaran, Z.; Seijo, L.; Huzinaga, S.; Klobukowski, M. Int. J. Quant. Chem. 1986, 29, 1047.

(34) Ziegler, T.; Tschinke, V.; Becke, A. J. Am. Chem. Soc. 1987, 109, 1351 .

(35) Louwen, J. N.; Stufkens, D. J.; Oskam, A. J. Chem. Soc., Dalton Trans. 1984, 2683.
Table XIV. SOMO Energies and Ionization Potentials $(\mathrm{eV})$ of the Radicals MMe.DAB

\begin{tabular}{cccc}
\hline $\mathrm{M}$ & $\mid E_{\text {SOMol }}$ & $\Delta S C F$ & exp. \\
\hline $\mathrm{Zn}$ & 6.99 & 6.09 & 5.89 \\
$\mathrm{Mg}$ & 7.10 & 6.23 & \\
\hline
\end{tabular}

${ }^{a}$ See ref 35 .

Table XV. Approximate RHF and UHF Spin Densities for Different Paramagnetic Species

\begin{tabular}{|c|c|c|c|c|c|c|}
\hline \multirow[b]{2}{*}{$\mathrm{M}$} & \multicolumn{3}{|c|}{ RHF } & \multicolumn{3}{|c|}{ UHF } \\
\hline & $N$ & $C_{\mathrm{R}}$ & $M$ & $N$ & $C_{\mathrm{R}}$ & $M$ \\
\hline $\begin{array}{l}\mathrm{Zn} \\
\mathrm{Mg}\end{array}$ & $\begin{array}{l}0.221 \\
0.221\end{array}$ & $\begin{array}{l}\text { (a) N } \\
0.259 \\
0.261\end{array}$ & $\begin{array}{c}\text { Me-DAB } \\
0.040 \\
0.037\end{array}$ & $\begin{array}{c}\text { Radicals } \\
0.411 \\
0.402\end{array}$ & $\begin{array}{l}0.143 \\
0.149\end{array}$ & $\begin{array}{l}0.006 \\
0.011\end{array}$ \\
\hline $\begin{array}{l}\mathrm{Zn} \\
\mathrm{Mg}\end{array}$ & $\begin{array}{l}0.232 \\
0.269\end{array}$ & $\begin{array}{c}\text { b) MMe } \\
0.261 \\
0.220\end{array}$ & $\begin{array}{c}\text { DAB A } \\
0.010 \\
0.020\end{array}$ & $\begin{array}{c}\text { ion Radi } \\
0.478 \\
0.537\end{array}$ & $\begin{array}{l}\text { als } \\
0.106 \\
0.025\end{array}$ & $\begin{array}{l}-0.047 \\
-0.027\end{array}$ \\
\hline
\end{tabular}

isoelectronic to the $\mathrm{MgMe}_{2} \cdot \mathrm{DAB}^{--}$radical anion discussed in this work) is overestimated by more than $2 \mathrm{eV}$ in the MNDO calculations; Koopmans' theorem was employed. ${ }^{35}$ While these authors explained this fact with deficiencies in the MNDO parametrization, one has to be aware that Koopmans' theorem is not valid for open-shell species within the RHF scheme. For a comparison Table XIV lists the SOMO energies and the $\triangle$ SCF values for the two MMe.DAB radical complexes studied in the present work. For $\mathrm{M}=\mathrm{Zn}$ the experimental value is also given. ${ }^{35}$ Obviously the $\triangle \mathrm{SCF}$ value is to be preferred over the SOMO energy. The very good agreement with experiment in the case of $\mathrm{M}=\mathrm{Zn}$ may indicate a small contribution from electron correlation.

As pointed out in the ESR section (see above) spin densities deduced from ESR coupling constants served as an argument for the selective $\mathrm{N}$-alkylation by $\mathrm{R}^{\prime}=\mathrm{Me}, \mathrm{Et}: \mathrm{:}^{2 \mathrm{f}}$ For the kinetically controlled reaction of these very reactive alkyl radicals $\mathrm{Me}^{*}$ and $\mathrm{Et}^{\circ}$, the relative spin densities on the different centers should play an important role. For a calculation of reliable spin densities, however, all-electron calculations with extensive electron correlation would have to be performed; such calculations are still out of reach for the systems studied here. Limited information can be drawn from a population analysis of the SOMO for the RHF wave function (which does not include spin polarization effects) or from a difference population for a UHF wave function (which does include some spin polarization effects but suffers from spin contamination $^{27}$ ). The results from both approximations for the MMe-DAB radical complexes and for the $\mathrm{MMe}_{2}$ radical anions are summarized in Table XV. Obviously the RHF values cannot reproduce the relative order of experimental spin densities for the neutral radicals, whereas the UHF values seem to overestimate spin polarization effects. In agreement with experiment both methods do show small spin densities on the metals and negligible differences between the two metals for the neutral radicals. No spin density on the protons of the alkyl group is found to explain the experimentally observed proton splitting for the neutral radicals. However, the calculation of small spin polarization effects $(<1 \%)$ in the $\sigma$ substituents is clearly beyond the scope of the 
Table XVI. Internal Coordinates of N-Alkylation Products

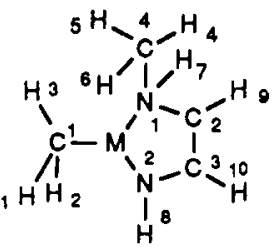

\begin{tabular}{|c|c|c|c|c|c|}
\hline & $M=Z n$ & $M=N$ & & $\mathrm{M}=\mathrm{Zn}$ & $\mathrm{M}=\mathrm{Mg}$ \\
\hline \multicolumn{6}{|c|}{ Distances, pm } \\
\hline $\mathrm{MCl}$ & 196 & 202 & $\mathrm{~N} 2 \mathrm{C} 3$ & 136 & 135 \\
\hline MNI & 224 & 218 & $\mathrm{C} 2 \mathrm{C} 3$ & 135 & 134 \\
\hline MN2 & 188 & 189 & $\mathrm{C} 4 \mathrm{~N} 1$ & 149 & 149 \\
\hline $\mathrm{N} 1 \mathrm{C} 2$ & 147 & 147 & & & \\
\hline \multicolumn{6}{|c|}{ Angles, deg } \\
\hline N1MN2 & 84 & 86 & $\mathrm{MN} 2 \mathrm{C} 3$ & 115 & 112 \\
\hline NIMCl & 136 & 137 & $\mathrm{~N} 1 \mathrm{C}_{2} \mathrm{C}_{3}$ & 119 & 119 \\
\hline $\mathrm{N} 2 \mathrm{MCl}$ & 140 & 137 & $\mathrm{~N} 2 \mathrm{C} 3 \mathrm{C} 2$ & 121 & 122 \\
\hline $\mathrm{MN} 1 \mathrm{C} 2$ & 101 & 101 & C4N1M & 118 & 118 \\
\hline \multicolumn{6}{|c|}{ Dihedral Angles, deg } \\
\hline $\mathrm{N} 1 \mathrm{C} 2 \mathrm{C} 3 \mathrm{~N} 2$ & 1.5 & 0.4 & $\mathrm{C} 3 \mathrm{~N} 2 \mathrm{MCl}$ & 176 & 176 \\
\hline $\mathrm{C} 2 \mathrm{~N} 1 \mathrm{MCl}$ & 177 & 176 & $\mathrm{C} 4 \mathrm{~N} / \mathrm{MCl}$ & 57 & 57 \\
\hline
\end{tabular}

Table XVII. Internal Coordinates of C-Alkylation Products

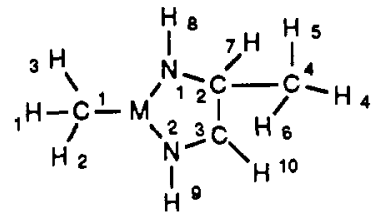

\begin{tabular}{|c|c|c|c|c|c|}
\hline & $\mathrm{M}=\mathrm{Zn}$ & $M=M$ & & $\mathrm{M}=\mathrm{Zn}$ & $\mathrm{M}=\mathrm{Mg}$ \\
\hline \multicolumn{6}{|c|}{ Distances, pm } \\
\hline $\mathrm{MCl}$ & 195 & 202 & $\mathrm{~N} 2 \mathrm{C} 3$ & 127 & 126 \\
\hline MN1 & 186 & 186 & $\mathrm{C} 2 \mathrm{C} 3$ & 153 & 152 \\
\hline MN2 & 215 & 210 & $\mathrm{C} 4 \mathrm{C} 2$ & 157 & 155 \\
\hline $\mathrm{N} 1 \mathrm{C} 2$ & 144 & 142 & & & \\
\hline \multicolumn{6}{|c|}{ Angles, deg } \\
\hline N1MN2 & 82 & 83 & $\mathrm{MN} 2 \mathrm{C} 3$ & 110 & 110 \\
\hline $\mathrm{N} 1 \mathrm{MCl}$ & 147 & 145 & $\mathrm{~N} 1 \mathrm{C} 2 \mathrm{C} 3$ & 108 & 109 \\
\hline $\mathrm{N} 2 \mathrm{MCl}$ & 131 & 132 & $\mathrm{~N} 2 \mathrm{C}_{3} \mathrm{C}_{2}$ & 120 & 121 \\
\hline $\mathrm{MN} 1 \mathrm{C} 2$ & 120 & 118 & $\mathrm{C} 4 \mathrm{C}_{2} \mathrm{C} 3$ & 111 & 111 \\
\hline \multicolumn{6}{|c|}{ Dihedral Angles, deg } \\
\hline $\mathrm{N} 1 \mathrm{C} 2 \mathrm{C} 3 \mathrm{~N} 2$ & 2.5 & 2.3 & $\mathrm{C} 3 \mathrm{~N} 2 \mathrm{MCl}$ & 180 & 180 \\
\hline $\mathrm{C} 2 \mathrm{~N} 1 \mathrm{MCl}$ & 179 & 178 & C4C2N1M & 128 & 128 \\
\hline
\end{tabular}

methods employed. Both methods yield higher spin densities on $\mathbf{N}$ for the radical anions than for the MMe-DAB radical complexes. This is in agreement with ESR spectral analysis (see above). Both methods also indicate a stronger polarization of the ligand in the $\mathrm{MgMe}_{2} \cdot \mathrm{DAB}$ radical anion than for its zinc analogue.

(f) The Alkylation Products. The geometries of the optimized $\mathrm{N}$ - and $\mathrm{C}$-alkylation products 5 and 6 with $\mathrm{R}^{\prime}=\mathrm{Me}(\mathrm{M}=\mathrm{Zn}$, $\mathrm{Mg}$ ) are summarized in Tables XVI and XVII. The MC distances are close to those in the neutral radical complexes which is consistent with an $\mathrm{MMe}^{+}$fragment and an anionic ligand.

For the C-alkylation products the extremely short $\mathrm{MN}_{1}$ distances indicate a high negative charge on $N_{1}$ which supports a description as a complex with an $\alpha$-amino-amido ligand (see Figure 9). The $\mathrm{C}_{2} \mathrm{C}_{3}$ and $\mathrm{N}_{1} \mathrm{C}_{2}$ distances are in the range of single bonds whereas the $\mathrm{N}_{2} \mathrm{C}_{3}$ bond retains the imine character. The $\mathrm{MN}_{2}$ bond is about $15 \mathrm{pm}$ shorter than that for the primary complexes; this might be caused by the three-coordination of the metal.

For the $\mathrm{N}$-alkylation products the $\mathrm{MN}_{2}$ bond is very short; but in this case a certain delocalization of charge into the $\mathrm{C}_{2} \mathrm{C}_{3}$ bond seems possible which should lead to a slightly lower nucleophilicity of $\mathrm{N}_{2}$. The $\mathrm{C}_{2} \mathrm{C}_{3}$ distances indicate a $\mathrm{CC}$ double bond whereas the $\mathrm{C}_{3} \mathrm{~N}_{2}$ distances lie between single and double bond values. Together with an almost planar chelate ring this supports a three-center delocalization. ${ }^{36}$ The $\mathrm{MN}_{1}$ bonds are somewhat
Table XVIII. Energies (au) of the Highest Occupied Canonical MOs for the Secondary Complexes

\begin{tabular}{llllll}
\hline & \multicolumn{2}{c}{$\mathrm{N}$-alkylation products } & & \multicolumn{2}{c}{ C-alkylation products } \\
\cline { 2 - 3 } \cline { 5 - 6 } & $\mathrm{M}=\mathrm{Zn}$ & $\mathrm{M}=\mathrm{Mg}$ & & $\mathrm{M}=\mathrm{Zn}$ & $\mathrm{M}=\mathrm{Mg}$ \\
\hline HOMO & -0.2728 & -0.2755 & -0.3095 & -0.3101 \\
$\sigma-\mathrm{MC}$ & -0.3524 & -0.3296 & -0.3429 & -0.3219 \\
\hline
\end{tabular}

Table XIX. Relative Energies ( $\mathrm{kJ} / \mathrm{mol})$ of Primary and Secondary Complexes $\left(R^{\prime}=\mathrm{Me}\right)$

\begin{tabular}{cccc}
\hline$M$ & $E^{\text {C-Alk. }}$ & $E^{\text {N-Alk. }}$ & $E^{\text {Prim }}$ \\
\hline $\mathrm{Zn}_{\mathrm{Mg}}$ & 0 & 9.6 & 152.2 \\
& 0 & 10.0 & 167.6 \\
\hline
\end{tabular}

shorter than those for the primary complexes and indicate coordinative bonds to an amine. Thus, a description as an enamine-amido complex with contribution from a carbanionic resonance structure with negative charge on $\mathrm{C}_{2}$ seems to be a good approximation (see Figure 9). The presence of amide nitrogens in both alkylation products and the delocalized enolate-type structure for the $\mathrm{N}$-alkylation products receive further support by Mulliken charges, and significant off-diagonal elements of the Fock matrix in the basis of localized ${ }^{26}$ MOs (for the N-alkylation products)

The energies of the two highest occupied canonical orbitals are listed in Table XVIII. The one with the lower energy in each case is mostly localized within the MMe fragment, consistent with higher orbital energies for $\mathbf{M}=\mathbf{M g}$. For the $\mathrm{N}$-alkylation products the HOMO is delocalized almost over the entire chelate ring with the highest $\mathrm{AO}$ coefficients on the amido nitrogen atom $\mathrm{N}_{2}$ and on $\mathrm{C}_{2}$. For the $\mathrm{C}$-alkylation products, by far the largest contribution is found on the amido nitrogen atom $\mathrm{N}_{1}$ with smaller coefficients on other atomic centers within the ring. The Koopmans' ionization potentials center around $7.5 \mathrm{eV}$ for the $\mathrm{N}$-alkylation products and around $8.4 \mathrm{eV}$ for the $\mathrm{C}$-alkylation products.

Although correlation and zero-point vibrational energy contributions were neglected in our calculations, the valence-energy differences for primary and secondary (i.e. alkylated) complexes (see Table XIX) should give an impression of the energetic situation before and after alkyl transfer. As expected, the alkylation products 5 and 6 are significantly lower in energy than the primary complexes 3, while the energy difference between the $\mathrm{N}$ - and $\mathrm{C}$-alkylation products is only a few $\mathrm{kJ} / \mathrm{mol}$. The larger differences between primary and secondary complexes for $\mathrm{M}=\mathrm{Mg}$ might either be caused by the neglect of electron correlation or be an indicator for the lower stability of the magnesium precursors 3 .

\section{General Discussion}

Within the mechanistic concept of single electron transfer reactivity between organometallics and organic substrates in solution, there are two basic ways to effect electron exchange starting from high-energy inner-sphere precursor complexes. First the system may be irradiated to produce charge transfer excited complexes which may then-to a varying extent (quantum yield)-convert to ground-state pairs of radicals confined within a solvent cage. As another possibility electron exchange may simply occur thermally, i.e. in the electronic ground state. For the systems studied in this work both possibilities have been demonstrated.

As indicated by the $\mathrm{ZnC}$ distances (e.g. in $\mathrm{ZnMe}_{2} \cdot \mathrm{DAB}$ ), the $\mathrm{ZnC}$ bond is weakened even in the ground state of the primary complex 3 , as compared to dimethylzinc 2 itself (cf. Table VI). In the radical anion 8 the bond is still weaker, and the $\mathrm{ZnC}$ distance for the $T_{1}$ state $3^{*}$ is clearly beyond normal covalent $\mathrm{ZnC}$ distances (cf. Table X). This trend is paralleled by the decrease in the $\mathrm{CZnC}$ angle.

If we assume that the allowed $S_{0} \rightarrow S_{1}$ transition is followed by a fast, heavy atom supported ISC process, the $T_{1}$ state will be the starting point for the photochemistry in these systems.

(36) Noltes, J. G.; t. Hoedt, R. W. M.; v. Koten, G.; Spek, A. L.; Schoone, J. C. J. Organomet. Chem. 1982, 225, 365 . 
Following this, the calculated $T_{1}$ state structure indicates an extremely low barrier to $\mathrm{ZnC}$ bond dissociation, leading to the earlier discussed radical pair 4 (Scheme I) with minimal structural changes. It has to be noted, however, that now this is a triplet radical pair and recombination to the alkylation products requires a preceding-possibly rate-determining-spin flip. This will lead to an increased lifetime for the radical pair, favoring escape processes. The fact that irradiation increases the amount of paramagnetic byproducts 7 supports this view.

On the other hand, the barrier to $\mathrm{ZnC}$ bond dissociation for the thermal reaction is expected to be significantly higher so that a concerted process may compete with the two-step process via radical pairs. In this case, many factors such as substituent characteristics, solvent effects, or temperature may control what mechanism is actually operating. For $\mathrm{M}=\mathrm{Mg}$ the extremely weak MC bond and the apparently smaller HOMO-LUMO gap might cause the domination of the two-step process which would explain the high amount of radical products and the lack of selectivity.

A nondissociative intramolecular process will require an approximately trigonal-pyramidal transition state, which would be subject to significant crowding when bulky substituents are involved. We have found that for $\mathbf{R}^{\prime}=0$-xylyl, mesityl, i.e. for substituents that have a high steric demand on the front side of binding, the thermal reaction is effectively prevented. However, irradiation into the LLCT band produces the strain-free radical complex 7. The phenyl analogue, irradiated in THF, yields the radical anion 8 that may be expected to exhibit a smaller $\mathrm{CZnC}$ angle than the corresponding ground-state primary complex (cf. Tables VI and $\mathrm{X}$ ). For $\mathrm{R}^{\prime}=t$-Bu the radical 7 formed thermally in ether $(<200 \mathrm{~K})$ converts slowly to the radical anion 8 (cf. Table $\mathrm{V})$. Apparently the globular shape of $t$-Bu, without steric demand on the front side, permits such coexistence of four bulky $t$-Bu groups.

The fact that the photochemical reactions yield a significantly changed ratio between the two possible alkylation products also supports the assumption that the operating mechanism is significantly different from the one occurring in the thermal reaction. The calculations indicate the two possible alkylation products to be relatively close in energy (cf. Table XIX). For the regioselectivity thermodynamic aspects should thus be less important than the exact course of the reaction mechanism.

Together with experimental data, ab initio pseudopotential calculations have yielded new insights into the chemistry of synthetically useful organozinc and -magnesium compounds. The unusual spectroscopic properties and the varying reactivity in the $\mathrm{MR}_{2}{ }^{\circ}$ (R-DAB) systems studied may be related to a small HOMO-LUMO gap in the chelate precursor complexes. The frontier orbital gap is particularly strongly influenced by all factors that control the MC $\sigma$ system of the organometallic fragment. Even the hyperconjugative effect of alkyl substitution has dramatic consequences for color and reactivity in these systems. Substitution of $\mathrm{Zn}$ by $\mathrm{Mg}$ both destabilizes the HOMO and stabilizes the LUMO. Accordingly the higher reactivity of the magnesium complexes leads to a lower selectivity of the reaction. The LUMO also is influenced by substitution at the imine nitrogen atoms.

Together with the possibility of changing the mechanism and product selectivity considerably by irradiation into the charge transfer band, the controlled variation of all these factors should allow a significant extension of this synthetically important reaction type. There is no doubt that accompanying theoretical studies, especially if extended to transition-state calculations, will contribute to the successful planning of experiments.

Acknowledgment. This work was supported by grants from Volkswagenstiftung (program Organometallic Reactions for Organic Synthesis), Land Baden-Württemberg (program Pseudopotentiale), from NATO, and the Netherlands Foundation for Chemical Research (SON) with financial aid from the Netherlands Organization for Scientific Research (NWO) to E.W. We thank Prof. H. J. Werner (Universität Bielefeld) for providing his Cray-2 version of the MOLPRo program.

Supplementary Material Available: Tables of anisotropic thermal parameters, hydrogen atom positions and isotropic thermal parameters, bond distances and angles, and selected torsion angles for $\mathrm{C}_{12} \mathrm{H}_{26} \mathrm{~N}_{2} \mathrm{Zn}$ ( 5 pages). Ordering information is given on any current masthead page. 